\title{
Interaction of aerosol particles composed of protein and salts with water vapor: hygroscopic growth and microstructural rearrangement
}

\author{
E. Mikhailov ${ }^{1,2}$, S. Vlasenko ${ }^{2}$, R. Niessner ${ }^{1}$, and U. Pöschl ${ }^{1}$ \\ ${ }^{1}$ Technical University of Munich, Institute of Hydrochemistry, Marchioninistr. 17, D-81377 Munich, Germany \\ ${ }^{2}$ Atmospheric Physics Department, Institute of Physics, St. Petersburg State University, Ulianovskaya 1, 198904 St. \\ Petersburg, Russia \\ Received: 15 July 2003 - Published in Atmos. Chem. Phys. Discuss.: 22 September 2003 \\ Revised: 9 February 2004 - Accepted: 13 February 2004 - Published: 17 February 2004
}

\begin{abstract}
The interaction of aerosol particles composed of the protein bovine serum albumin (BSA) and the inorganic salts sodium chloride and ammonium nitrate with water vapor has been investigated by hygroscopicity tandem differential mobility analyzer (H-TDMA) experiments complemented by transmission electron microscopy (TEM) and Köhler theory calculations $(100-300 \mathrm{~nm}$ particle size range, $298 \mathrm{~K}, 960 \mathrm{hPa}$ ). BSA was chosen as a well-defined model substance for proteins and other macromolecular compounds, which constitute a large fraction of the water-soluble organic component of air particulate matter.

Pure BSA particles exhibited deliquescence and efflorescence transitions at $\sim 35 \%$ relative humidity $(R H)$ and a hygroscopic diameter increase by up to $\sim 10 \%$ at $95 \% R H$ in good agreement with model calculations based on a simple parameterisation of the osmotic coefficient. Pure $\mathrm{NaCl}$ particles were converted from near-cubic to near-spherical shape upon interaction with water vapor at relative humidities below the deliquescence threshold (partial surface dissolution and recrystallisation), and the diameters of pure $\mathrm{NH}_{4} \mathrm{NO}_{3}$ particles decreased by up to $10 \%$ due to chemical decomposition and evaporation.
\end{abstract}

Mixed NaCl-BSA and $\mathrm{NH}_{4} \mathrm{NO}_{3}$-BSA particles interacting with water vapor exhibited mobility equivalent diameter reductions of up to $20 \%$, depending on particle generation, conditioning, size, and chemical composition (BSA dry mass fraction 10-90\%). These observations can be explained by formation of porous agglomerates (envelope void fractions up to $50 \%$ ) due to ion-protein interactions and electric charge effects on the one hand, and by compaction of the agglomerate structure due to capillary condensation effects on the other. The size of $\mathrm{NH}_{4} \mathrm{NO}_{3}$-BSA particles was appar-

Correspondence to: U. Pöschl

(ulrich.poeschl@ch.tum.de) ently also influenced by volatilisation of $\mathrm{NH}_{4} \mathrm{NO}_{3}$, but not as much as for pure salt particles, i.e. the protein inhibited the decomposition of $\mathrm{NH}_{4} \mathrm{NO}_{3}$ or the evaporation of the decomposition products $\mathrm{NH}_{3}$ and $\mathrm{HNO}_{3}$. The efflorescence threshold of NaCl-BSA particles decreased with increasing BSA dry mass fraction, i.e. the protein inhibited the formation of salt crystals and enhanced the stability of supersaturated solution droplets.

The H-TDMA and TEM results indicate that the protein was enriched at the surface of the mixed particles and formed an envelope, which inhibits the access of water vapor to the particle core and leads to kinetic limitations of hygroscopic growth, phase transitions, and microstructural rearrangement processes.

The Köhler theory calculations performed with different types of models demonstrate that the hygroscopic growth of particles composed of inorganic salts and proteins can be efficiently described with a simple volume additivity approach, provided that the correct dry solute mass equivalent diameter and composition are known. A parameterisation for the osmotic coefficient of macromolecular substances has been derived from an osmotic pressure virial equation. For its application only the density and molar mass of the substance have to be known or estimated, and it is fully compatible with traditional volume additivity models for salt mixtures.

\section{Introduction}

The interaction of aerosol particles with water vapor and their activation as cloud condensation nuclei $(\mathrm{CCN})$ are among the central issues of current research in atmospheric and climate science. Aerosols can scatter or absorb radiation, influence the formation of clouds and precipitation, and affect 
the abundance of trace gases via heterogeneous chemical reactions and other multiphase processes (e.g. Andreae and Crutzen, 1997; Baker, 1997; Ravishankara, 1997; Seinfeld and Pandis, 1998; Finlayson-Pitts and Pitts, 2000; Ramanathan et al., 2001; Ramaswamy et al., 2001; Austin et al., 2003; Iziomon and Lohmann, 2003; Kulmala et al., 2003; and references therein). Moreover, they are of major importance with respect to air pollution control and can cause respiratory and cardiovascular diseases when deposited in the human respiratory tract (e.g. Finlayson-Pitts and Pitts, 1997; Seinfeld and Pandis, 1998; Finlayson-Pitts and Pitts, 2000; Pöschl, 2002; and references therein).

The primary parameters which determine the optical properties, $\mathrm{CCN}$ activity, reactivity, and deposition of aerosol particles are their size and composition. Depending on their sources and atmospheric processing (interaction with radiation, gases, and clouds), atmospheric particles consist of a complex mixture of organic and inorganic chemical components. Water can be adsorbed on the surface or contained in the bulk of the particles in variable amounts determined by the physico-chemical properties of the other particle components (wettability, water-solubility, hygroscopicity) and ambient conditions (temperature, relative humidity). The interaction of water-soluble inorganic salts and acids with water vapor is fairly well understood and considered to have a strong influence on atmospheric aerosol properties and effects (e.g. Pruppacher and Klett, 1997; Colberg et al., 2003; Martin et al., 2004; Pszenny et al., 2004; and references therein). For example, the critical supersaturation for cloud droplet formation on ultrafine aerosol particles composed of hygroscopic salts is much lower than for insoluble materials, and the scattering cross- sections of deliquesced ammonium sulfate particles at $90 \%$ relative humidity exceed those of dry particles by a factor of five or more (Tang, 1996; Malm and Day, 2001).

The understanding of the influence of organic compounds, however, is very limited (e.g. Pruppacher and Klett, 1997; Ming and Russell, 2001; Russell et al., 2002; Tsigaridis and Kanakidou, 2003; Ciczco, 2003; Martin and Bertram, 2003; Martin et al., 2004; Kärcher, 2004; Gysel et al., 2004; and references therein). Depending on sampling location and season, organics account for up to $50 \%$ or more of the dry mass of air particulate matter, but only a few percent of the individual compounds have been identified on a molecular level (e.g. Rogge et al., 1993; Saxena and Hildemann, 1996; Facchini et al., 1999a, Jacobson et al., 2000; Turpin et al. 2000; Matta et al., 2003; Pöschl, 2003; Sciare et al., 2003; Schneider et al., 2004; and references therein). Large fractions of the water-soluble organic particulate matter (up to $\sim 50 \%$ ) have been attributed to macromolecular compounds, including proteins and humic-like substances (Mukai and Ambe, 1986; Havers et al., 1998; Zappoli et al., 1999; Decesari et al., 2001). Proteins and protein derivatives account for up to $\sim 10 \%$ of water-soluble organic carbon in fog water and fine particulate matter (PM2.5), can act as surfactants, react with trace gases like ozone and nitrogen oxides, and affect public health as allergens (Miguel et al., 1999; Franze et al., 2001; Zhang and Anastasio, 2003; Franze et al., 2003a, 2003b).

Several laboratory studies have shown that particles composed of water-soluble organic compounds can take up water vapor and act as CCN (e.g. Cruz and Pandis, 1997; Corrigan and Novakov, 1999; Prenni et al., 2001; Prenni et al., 2003; Kumar et al., 2003). Organic surfactants can decrease the surface tension of aqueous droplets, enhance hygroscopic growth, reduce the critical supersaturation for cloud droplet formation, and enhance cloud albedo (Shulman et al., 1996; Facchini et al., 1999b). On the other hand, organic surface layers can inhibit the uptake of water vapor by liquid aerosol particles and influence the wettability of solid aerosol particles (e.g. Gill et al., 1983; Niessner and Helsper, 1985; Niessner et al., 1989; Hansson et al., 1990; Hämeri et al., 1992; Andrews and Larson, 1993; Saxena et al., 1995; Xiong et al., 1998; Kotzick and Niessner, 1999).

To our knowledge, however, only a couple of experimental studies investigating the effect of macromolecular organic compounds on the hygroscopicity of atmospheric particles have been published (Chan and Chan, 2003; Gysel et al., 2004), and these were focused on humic-like substances. No experimental data for proteins and no Köhler theory models for this type of substances have been presented up to now.

Therefore, we have set out to investigate and characterise the hygroscopic growth of aerosol particles in the 100$200 \mathrm{~nm}$ size range composed of the protein bovine serum albumin (BSA) and the inorganic salts sodium chloride and ammonium nitrate by laboratory experiments and model calculations. BSA was chosen as a well-defined model substance for proteins and other macromolecular organic compounds. It is a globular protein with a molecular diameter on the order of $\sim 5 \mathrm{~nm}$ and a molar mass of $\sim 66.5 \mathrm{~kg} / \mathrm{mol}$, composed of a polypeptide chain of 583 natural $\alpha$-aminoacid residues (Tanford, 1961; NCBI database, www.ncbi.nlm.nih. gov, AAN17824).

The experimental investigations have been performed with a hygroscopicity tandem differential mobility analyzer (HTDMA) and complemented by transmission electron microscopy (TEM). The principles of TDMA experiments have been described a couple of decades ago (Liu et al., 1978; Rader and McMurry, 1986), and a wide range of applications and modifications of this technique have been reported since then (e.g. Cruz et al., 2000; Hämeri, et al., 2000; Krämer et al., 2000; Joutsensaari et al., 2001; Weingartner et al., 2002; Väkevä et al., 2002; Maßling et al., 2003). The instrumentation and measurement procedures applied in this study are described below. Moreover, different models for Köhler theory calculations of the hygroscopic growth of particles containing inorganic salts and proteins or comparable organic macromolecules are outlined and tested against the experimental results. 


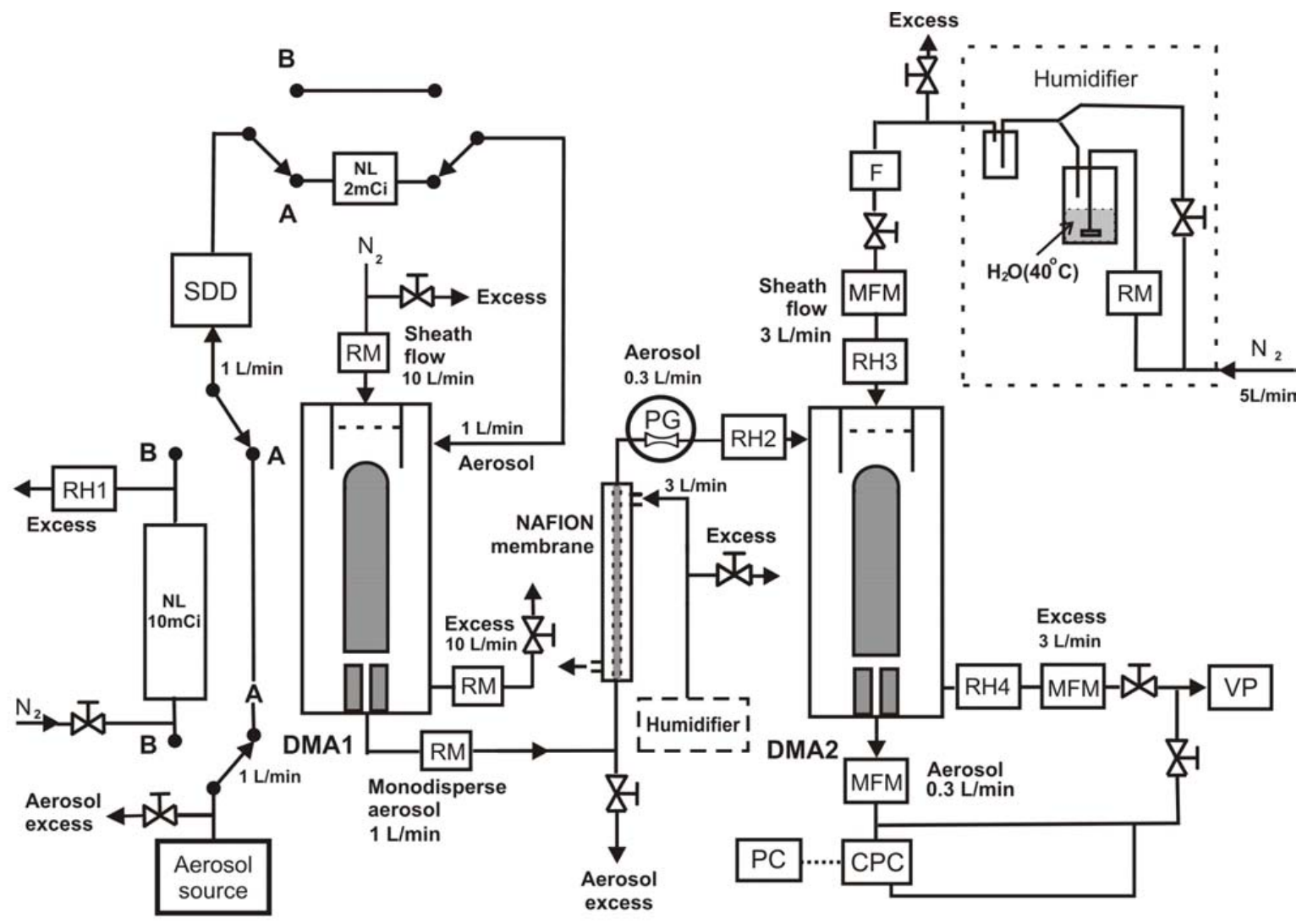

Fig. 1. Experimental setup of the hygroscopicity tandem differential mobility analyzer (H-TDMA) system: RH - relative humidity sensor, $\mathrm{NL}$ - aerosol neutralizer, SDD - silica gel diffusion dryer, RM - rotameter, DMA - differential mobility analyzer, PG - impactor and pressure gauge, MFM - mass flow meter, F - filter, CPC - condensation particle counter, $\mathrm{PC}$ - personal computer, VP - vacuum pump.

\section{Experimental}

Aerosols were generated by nebulisation of an aqueous solution of the investigated pure substance or substance mixture (mass fraction $0.1 \%$ ). The solutions were prepared by dissolving the appropriate amounts of bovine serum albumin (BSA, fraction $\mathrm{V},>96 \%$, Sigma), sodium chloride, and ammonium nitrate $\left(\mathrm{NaCl}, \mathrm{NH}_{4} \mathrm{NO}_{3},>99.5 \%\right.$, Merck) in $250 \mathrm{~mL}$ of deionised water $(18.2 \mathrm{M} \Omega \mathrm{cm}$, Milli Q plus 185 , Millipore). The molecular masses of the investigated compounds and their densities at $298 \mathrm{~K}$ are summarised in Table 1 . The applied cross-flow nebuliser (glass, self-made) was operated with a nitrogen carrier gas flow of $3.0 \mathrm{~L} / \mathrm{min}$. (99.999\%, Messer-Griesheim) in a $500 \mathrm{~mL}$ three-neck glass flask containing the aqueous solution. $1.0 \mathrm{~L} / \mathrm{min}$ of the generated aerosol flow was fed into the H-TDMA setup illustrated in Fig. 1. Antistatic tubing (Tygon, Norton) was used for all aerosol and gas flows. The gas flow rates were measured with rotameters (Rota Yokogawa) calibrated with a bubble flow meter (Gillian Gilibrator 2, Sensidyne, accuracy $\pm 1 \%$ ) and adjusted with needle valves (brass/steel, self-made) and tube clips (Roth). All H-TDMA experiments were performed at ambient temperature and pressure $(298 \pm 2 \mathrm{~K}, 960 \mathrm{hPa})$.
Table 1. Molecular mass and density at $298 \mathrm{~K}$ for the investigated compounds (Weast, 1998; bovine serum albumin (BSA): Tanford, 1961).

\begin{tabular}{ccccc}
\hline & $\mathrm{H}_{2} \mathrm{O}$ & $\mathrm{NaCl}$ & $\mathrm{NH}_{4} \mathrm{NO}_{3}$ & $\mathrm{BSA}$ \\
\hline$M\left(\mathrm{~kg} \mathrm{~mol}^{-1}\right)$ & 0.01802 & 0.05844 & 0.08004 & 66.5 \\
$\rho\left(\mathrm{kg} \mathrm{m}^{-3}\right)$ & 997.1 & 2165 & 1725 & 1362 \\
\hline
\end{tabular}

Two different operation modes were applied in the process of initial aerosol drying and neutralisation.

Neutralisation mode A: Usually the aerosol flow from the nebuliser flask was directly fed into a silica gel diffusion drier (SDD, self-made: fine steel mesh tube with $50 \mathrm{~cm}$ length and $1 \mathrm{~cm}$ i.d. surrounded by dense packing of silica gel in glass jacket with $10 \mathrm{~cm}$ i.d.), subsequently passed through a neutraliser $\left({ }^{85} \mathrm{Kr}, 2 \mathrm{mCi}\right.$, TSI, Model 3077), and introduced into the first differential mobility analyzer, DMA 1 (self-made, similar to TSI Model 3071). Neutralisation mode A was applied for all experiments reported below unless mentioned otherwise. 
Neutralisation mode B: For some test experiments the aerosol flow from the nebuliser flask was passed through a neutraliser $\left({ }^{85} \mathrm{Kr}\right.$, $10 \mathrm{mCi}$ TSI Model 3054$)$ before entering the SDD and DMA 1. To avoid water condensation inside the neutraliser, the aerosol flow was slightly diluted by dry nitrogen $(\sim 0.2 \mathrm{~L} / \mathrm{min})$. The relative humidity, $R H$, of the diluted (excess) flow was kept at or below $85 \%$. The capacitive humidity sensors $\left(\mathrm{RH}_{1}-\mathrm{RH}_{4}\right.$, Ahlborn FH A646, accuracy $\pm 2 \% R H$, precision $\pm 0.5 \%$ ) were also used to measure the temperature (accuracy $\pm 0.1 \mathrm{~K}$ ) of gas and aerosol flows in the H-TDMA system (Fig. 1).

DMA 1 was operated with a dry nitrogen sheath gas flow of $10 \mathrm{~L} / \mathrm{min}$, and by electrostatic classification a dry monodisperse aerosol with a geometric standard deviation of $\sigma_{g}<1.1$ was selected. $0.3 \mathrm{~L} / \mathrm{min}$ of the mondisperse aerosol flow were passed through a conditioner tube (length, $170 \mathrm{~cm}$, i.d. $0.25 \mathrm{~cm})$ to adjust the relative humidity $\left(\mathrm{RH}_{2}\right)$ by exchange of water vapor with a humidified nitrogen gas flow through a semi-permeable membrane (Nafion, Ansyco). The residence time of the aerosol flow in the conditioner and in the subsequent line leading to DMA 2 was $11 \mathrm{~s}$ (conditioning time).

The size distribution of the conditioned particles was measured with a scanning mobility particle sizer SMPS (DMA 2, TSI Model 3071; CPC TSI 3025; TSI AIM 4.3 software; aerosol inflow $0.3 \mathrm{~L} / \mathrm{min}$; pre-impactor nozzle $0.0508 \mathrm{~cm}$; size range $14.8-487 \mathrm{~nm}$; upscan time $120 \mathrm{~s}$; retrace time $15 \mathrm{~s}$; delay time $10 \mathrm{~s}$; CPC flow $0.3 \mathrm{~L} / \mathrm{min}$ and count time $0.1 \mathrm{~s}$ ). DMA 2 was operated with a nitrogen sheath gas flow of $3.0 \mathrm{~L} / \mathrm{min}$ with adjustable relative humidity $\left(\mathrm{RH}_{3}\right)$, which was controlled by mixing of dry nitrogen with a nitrogen gas flow saturated with water vapor. Two independent humidifier units were used for the sheath gas flow of DMA 2 and for the conditioner flow. The residence time of the aerosol flow in DMA 2 was $7.5 \mathrm{~s}$.

The experimental setup allowed to run the combination of conditioner tube and DMA 2 in three different H-TDMA operation modes and to investigate three different processes:

H-TDMA mode 1 ("hydration"): In this mode $\mathrm{RH}_{3}$ was varied from 0 to $\sim 95 \%$ with $\mathrm{RH}_{2} \approx 0.98 \mathrm{RH}_{3}$. Keeping $\mathrm{RH}_{2}$ lower than $\mathrm{RH}_{3}$ allowed to study the hygroscopic growth, restructuring, and deliquescence of dry particles without hysteresis effects.

H-TDMA mode 2 ("dehydration"): In this mode $\mathrm{RH}_{3}$ was varied from 0 to $\sim 95 \%$ with $R H_{2} \approx 85 \%$ for $R_{3}<85 \%$ and $\mathrm{RH}_{2} \approx \mathrm{RH}_{3}$ for $\mathrm{RH}_{3}>85 \%$. Keeping $\mathrm{RH}_{2}$ above the deliquescence threshold allowed to study the hysteresis effect and efflorescence of deliquesced droplets.

$H$-TDMA mode 3 ("hydration \& dehydration"): In this mode $\mathrm{RH}_{2}$ was varied from 0 to $\sim 95 \%$ with $\mathrm{RH}_{3} \approx 0$ and $R H_{4}<10 \%$. Keeping $R H_{3} \approx 0$ and $R H_{4}<10 \%$ allows to study and compare the restructuring effects of humidification in the conditioner and drying in DMA 2 without droplet formation $\left(\mathrm{RH}_{2}<R \mathrm{H}_{\mathrm{d}}\right)$ or with intermediate droplet forma- tion involving a full hysteresis cycle of deliquescence and efflorescence $\left(R \mathrm{H}_{2}>R \mathrm{H}_{\mathrm{d}}\right)$.

The applicability of DMA 2 for both particle drying and sizing in the reported hydration \& dehydration experiments (H-TDMA mode 3 ) has been confirmed by test experiments in which the aerosol flow was dried to $\mathrm{RH}_{2}<5 \%$ before entering DMA 2. These experiments yielded essentially the same results and indicate near-instantaneous evaporation and efflorescence of solution droplets entering the DMA drift zone for electrostatic sizing in H-TDMA mode 3. Further investigations of phase transition kinetics and a detailed discussion of particle drying and sizing inside a DMA will be presented in a separate publication. This follow-up publication will also include analyses of size distribution standard deviations and broadening effects, which go beyond and are not required to support the conclusions of the present manuscript (Mikhailov et al., 2003).

Up to $R H \approx 90 \%$ the relative humidity of the sheath flow $\left(\mathrm{RH}_{3}\right)$ and exhaust of DMA $2\left(\mathrm{RH}_{4}\right)$ agreed to within $2 \%$. For $R H_{3}>90 \%, R H_{4}$ was lower by up to $4 \%$ due to small temperature gradients in the system (differences up to $0.5 \mathrm{~K}$ ). $\mathrm{RH}_{4}$ is considered to be most representative for the effective overall relative humidity in DMA 2 was thus used for all plots and calculations involving $R H$ unless mentioned otherwise. The modal diameters (local maxima) of the particle number size distributions measured with the SMPS system have been used for plots and calculations involving the particle mobility equivalent diameter $D_{\mathrm{b}}$. They were determined from B-Spline fits to the SMPS measurement data (Origin 7.0 software, CPC raw counts vs. mobility equivalent diameter, 64 channels per decade; Mikhailov et al., 2003). The mobility equivalent particle growth factor, $g_{\mathrm{b}}$, was calculated as the ratio of the mobility equivalent diameter measured after conditioning (hydration, dehydration, or hydration \& dehydration) to the initial mobility equivalent diameter of the particles selected by DMA $1, D_{\mathrm{b}, \mathrm{i}}\left(g_{\mathrm{b}}=D_{\mathrm{b}} / D_{\mathrm{b}, \mathrm{i}}\right) . D_{\mathrm{b}, \mathrm{i}}$ was measured at $R_{2} \approx R H_{3} \approx R H_{4} \approx 0$. The precision of particle diameter measurements was generally better than $\pm 1 \%$ (relative standard deviation of repeated measurements). The accuracy of particle sizing is estimated to be $\pm 2 \%$, which is confirmed by the good agreement of the measurement results for pure $\mathrm{NaCl}$ particles with literature data and model calculations.

In addition to the H-TDMA experiments with suspended particles, the morphology of deposited particles has been studied by transmission electron microscopy (TEM, EMMA100). The TEM samples were prepared in a system analogous to the setup described above, but instead of sizing with a DMA the aerosol particles were deposited with a thermophoretic precipitator (self-made) on $3 \mathrm{~mm}$ nickel grids covered with formvar film. The particles were sampled either at the output of the SDD with $R H \approx 35 \%$, or after passing through a glass conditioner tube (residence time $\sim 20 \mathrm{~s}$ ) with $R H=70 \%$ and a second SDD. Immediately after deposition the particles were transferred into a silica gel desiccator, and 
Table 2. Polynomial coefficients for the empirical parameterisations of the density and water activity of aqueous solutions of $\mathrm{NaCl}$ and $\mathrm{NH}_{4} \mathrm{NO}_{3}$ (Tang, 1996).

\begin{tabular}{lllllllll}
\hline Solute & $c_{1}$ & $c_{2}$ & $c_{3}$ & $c_{4}$ & $d_{1}$ & $d_{2}$ & $d_{3}$ & $d_{4}$ \\
\hline $\mathrm{NaCl}$ & -0.6366 & 0.8624 & -11.58 & 15.18 & 0.741 & -0.3741 & 2.252 & -2.06 \\
$\mathrm{NH}_{4} \mathrm{NO}_{3}$ & -0.365 & -0.09155 & -0.2826 & & 0.405 & -0.09 & & \\
\hline
\end{tabular}

kept under dry conditions for $10 \mathrm{~min}$ before transfer into the TEM high vacuum system. The relative humidity of the ambient air to which the particles were exposed in the course of the sampling and TEM analysis procedures was kept below $32 \%$.

\section{Theory and models}

3.1 Köhler theory and models of hygroscopic particle growth

According to Köhler theory, the relation between relative humidity and the size and composition of a spherical aqueous solution droplet suspended in a gas under equilibrium conditions can be described by (Pruppacher and Klett, 1997):

$S_{\mathrm{w}}=a_{\mathrm{w}} \exp \left(\frac{4 \sigma M_{\mathrm{w}}}{\rho R T D_{\mathrm{m}}}\right)$.

The water vapor saturation ratio $S_{\mathrm{w}}$ is defined as the ratio of the actual partial pressure of water vapor to the equilibrium water vapor pressure over a flat surface of pure water at the given temperature. The relative humidity $R H$ is identical to $S_{\mathrm{w}}$ expressed in percent. The activity of water in the solution droplet, $a_{\mathrm{w}}$, is defined as the ratio of equilibrium water vapor pressures over flat surfaces of the aqueous solution and of pure water. The exponential term of Eq. (1) is the socalled Kelvin or curvature term, which describes the increase of equilibrium water vapor pressure over a spherical droplet with the surface tension and the inverse of the droplet diameter $D_{\mathrm{m}}$ (geometric = mass equivalent diameter). $M_{\mathrm{w}}$ is the molar mass of $\mathrm{H}_{2} \mathrm{O} . R$ is the ideal gas constant, and $T$ is the absolute temperature. $\sigma$ and $\rho$ are the surface tension and density of the aqueous solution, respectively.

The ratio of the droplet diameter, $D_{\mathrm{m}}$, to the mass equivalent diameter of a particle consisting of the dry solute (dissolved substance), $D_{\mathrm{m}, s}$, is defined as the mass equivalent growth factor of the dry solute particle, $g_{\mathrm{m}, s}$ :

$g_{\mathrm{m}, s}=\frac{D_{\mathrm{m}}}{D_{\mathrm{m}, s}}=\left(\frac{\rho_{s}}{x_{s} \rho}\right)^{1 / 3}$.

$x_{s}$ is the mass fraction of the solute in the droplet, and $\rho_{s}$ is the density of the dry solute. Equations (1) and (2) can be used to describe the hygroscopic growth of aerosol particles $\left(D_{\mathrm{m}}\right.$ as a function of $D_{\mathrm{m}, s}$ and $\left.R H\right)$, if $a_{\mathrm{w}}, \rho$, and $\sigma$ are known as a function of droplet composition which is usually described by the mass fraction or molality of the solute. Solute molality, $\mu_{s}$, mass fraction, $x_{s}$, and molar mass, $M_{s}$, are related by:

$\mu_{s}=\frac{x_{s}}{M_{s}\left(1-x_{s}\right)}=\left(\left(\frac{1}{x_{s}}-1\right) M_{s}\right)^{-1}$.

\subsubsection{Full parameterisation (FP) models}

\subsubsection{Empirical parameterisations of $a_{\mathrm{w}}, \rho$, and $\sigma$}

For some inorganic salts experimental data of the density and water activity of aqueous solution droplets have been determined with single-particle levitation techniques (Tang, 2000, and references therein). Tang (1996) presented experimental values of $a_{\mathrm{w}}$ and $\rho$ as polynomial fit functions of solute mass fraction $x_{s}$ :

$a_{\mathrm{w}}=1+\sum_{q} c_{q} x_{s}^{q}$,

$\rho=\rho_{\mathrm{w}}+\sum_{q} d_{q} x_{s}^{q}$.

$\rho_{\mathrm{w}}$ is the density of pure water $\left(997.1 \mathrm{~kg} \mathrm{~m}^{-3}\right.$ at $\left.298 \mathrm{~K}\right)$. The polynomial coefficients $c_{q}$ and $d_{q}$ for $\mathrm{NaCl}$ and $\mathrm{NH}_{4} \mathrm{NO}_{3}$ at $298 \mathrm{~K}$ are listed in Table 2 . These polynomial fit functions are valid up to high salt supersaturations $\left(x_{\mathrm{NaCl}}=48 \%\right.$ and $x_{\mathrm{NH}_{4} \mathrm{NO}_{3}}=90 \%$, respectively). The increase of the surface tension of aqueous solution droplets with increasing concentration of inorganic salts can be described with the formula proposed by Hänel (1976). Test calculations, however, have shown that the Kelvin term in Eq. (1) can be approximated with $\rho=\rho_{\mathrm{w}}$ and $\sigma=\sigma_{\mathrm{w}}=0.072 \mathrm{~N} \mathrm{~m}^{-1}$ under the experimental conditions of this study $\left(298 \mathrm{~K}, D_{\mathrm{m}} \geq 100 \mathrm{~nm}\right)$. For pure $\mathrm{NaCl}$ particles the relative errors introduced by this simplifying assumption in the calculation of $R H$ from Eq. (1) were less than $0.1 \%$. Moreover, the increase of surface tension by inorganic salts is counteracted by surfactants such as proteins. In the FP model calculations which are based on the above empirical parameterisations and presented below for aqueous $\mathrm{NaCl}$ and $\mathrm{NH}_{4} \mathrm{NO}_{4}$ solution droplets, $x_{s}$ was taken as the primary variable to calculate $a_{\mathrm{w}}$ and $\rho$ from Eqs. (4) and (5). $\rho, \rho_{s}, M_{s}, x_{s}$, and $D_{\mathrm{m}, s}$ were inserted into Eq. (2) to obtain $D_{\mathrm{m}}$, and finally $D_{\mathrm{m}}, a_{\mathrm{w}}, M_{\mathrm{w}}, \sigma=\sigma_{\mathrm{w}}$, and $\rho=\rho_{\mathrm{W}}$ were inserted in Eq. (1) to calculate the corresponding equilibrium value of $R H$. 


\subsubsection{Ion-interaction parameterisations of $a_{\mathrm{w}}$}

According to Robinson and Stokes (1970) the water activity of aqueous solutions of ionic compounds can be described by:

$a_{\mathrm{w}}=\exp \left(-v_{s} \Phi_{s} \mu_{s} M_{\mathrm{w}}\right)$.

$v_{s}$ is the stoichiometric dissociation number of the solute, i.e. the number of ions per formula unit $\left(v_{\mathrm{NaCl}}=v_{\mathrm{NH}_{4} \mathrm{NO}_{3}}=2\right)$. $\Phi_{s}$ is the molal or practical osmotic coefficient of the solute in aqueous solution. It describes the non-ideality of the solution, i.e. ion interactions and other effects leading to deviations from Raoult's law $\left(\Phi_{s, \text { ideal }}=1\right)$. Based on an ion-interaction approach, Pitzer (1973) derived semiempirical parameterisations, which describe $\Phi_{s}$ as a function of solute molality $\mu_{s}$. The general form for strong electrolytes dissociating into two types of ions is

$$
\begin{aligned}
& \Phi_{s}=1-\left|z_{1} z_{2}\right|\left(A_{\Phi} \frac{\sqrt{I}}{1+b_{\mathrm{pit}} \sqrt{I}}\right) \\
& +\mu_{s} \frac{2 v_{1} v_{2}}{v_{s}}\left(\beta_{0}+\beta_{1} e^{-\alpha \sqrt{I}}\right) \\
& +\mu_{s}^{2} \frac{2\left(v_{1} v_{2}\right)^{3 / 2}}{v_{s}} C_{\Phi} .
\end{aligned}
$$

$\nu_{1}$ and $\nu_{2}$ are the numbers of positive and negative ions produced upon dissociation per formula unit of the solute $\left(v_{s}=v_{1}+v_{2}\right) ; z_{1}$ and $z_{2}$ are the numbers of elementary charges carried by the ions. At $298 \mathrm{~K}$ the parameters $\alpha$ and $b_{\text {pit }}$ are $2(\mathrm{~kg} / \mathrm{mol})^{1 / 2}$ and $1.2(\mathrm{~kg} / \mathrm{mol})^{1 / 2}$, respectively (Pitzer, 1973). The molal ionic strength is given by $I=0.5\left(\mu_{1} z_{1}^{2}+\mu_{2} z_{2}^{2}\right) . A_{\Phi}$ is the Debye-Hückel coefficient which equals $0.392(\mathrm{~kg} / \mathrm{mol})^{1 / 2}$ for water at $298 \mathrm{~K}$ (Pitzer and Mayorga, 1973). The coefficients $\beta_{0}, \beta_{1}$ and $C_{\Phi}$ depend on the chemical composition of the solute and have been tabulated by Pitzer and Mayorga (1973) for over $200 \mathrm{com}$ pounds (1:1, 1:2, and 2:1 electrolytes). For $\mathrm{NaCl}$ and some other inorganic salts of atmospheric relevance the above coefficients and their temperature dependence have been summarised by Gysel et al. (2002). For $\mathrm{NaCl}$ in $\mathrm{H}_{2} \mathrm{O}$ at $298 \mathrm{~K}$ the parameters are $v_{1}=v_{2}=z_{1}=z_{2}=1, \beta_{0}=0.1017 \mathrm{~kg} \mathrm{~mol}^{-1}$, $\beta_{1}=0.2769 \mathrm{~kg} \mathrm{~mol}^{-1}$, and $C_{\Phi}=-0.003227 \mathrm{~kg}^{2} \mathrm{~mol}^{-2}$ (Mokbel et al., 1997).

The FP model calculations for aqueous $\mathrm{NaCl}$ solution droplets based on the semi-empirical parameterisation of $\Phi_{\mathrm{NaCl}}$ by Eq. (7) and presented below were performed in analogy to the FP model calculations based on the empirical parameterisations described above (Sect. 3.1.1.1). Only $a_{\mathrm{w}}$ was calculated in a different way, namely by inserting $x_{\mathrm{NaCl}}$ and $M_{\mathrm{NaCl}}$ in Eq. (3), $\mu_{\mathrm{NaCl}}$ in Eq. (7), and $\mu_{\mathrm{NaCl}}, \Phi_{\mathrm{NaCl}}$, and $v_{\mathrm{NaCl}}$ and in Eq. (6).

Figure 2a shows $\Phi_{\mathrm{NaCl}}$ calculated with Eq. (7) and plotted against $\mu_{\mathrm{NaCl}}$ in comparison to the values which can be obtained from the empirical parameterisation of $a_{\mathrm{w}}$ using Eqs. (3), (4), and (6). The relative deviation exceeds
$5 \%$ at very low and very high molalities $\left(<0.1 \mathrm{~mol} \mathrm{~kg}^{-1}\right.$, $>8 \mathrm{~mol} \mathrm{~kg}^{-1}$ ).

Clegg, Pitzer and co-workers have extended the semiempirical parameterisations and developed a series of ioninteraction models for the calculation of the thermodynamic properties of highly concentrated aqueous solutions of inorganic salts relevant for the atmosphere (Aerosol Inorganics Model, AIM; Clegg and Pitzer, 1992; Wexler and Clegg, 2002) which are publicly available on the internet: http: //www.hpc1.uea.ac.uk/ e770/aim/aim.htm. In the FP model calculations presented below for aqueous $\mathrm{NH}_{4} \mathrm{NO}_{3}$ droplets, the current online version of AIM II (Clegg et al., 1998)

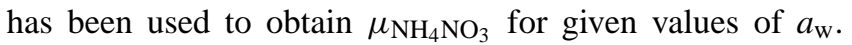
$\mu_{\mathrm{NH}_{4} \mathrm{NO}_{3}}$ and $M_{\mathrm{NH}_{4} \mathrm{NO}_{3}}$ were inserted into Eq. (3) to deter-

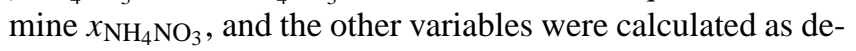
scribed above (Sect. 3.1.1.1).

\subsubsection{Volume additivity (VA) models}

Under the assumption that the volume of the solution droplet is given by the sum of the volumes of the dry solute and of the water contained in the droplet (volume additivity), the molality of the solute is given by (Pruppacher and Klett, 1997):

$\mu_{s}=\frac{m_{s}}{M_{s} m_{\mathrm{w}}}=\frac{\rho_{s} D_{\mathrm{m}, s}^{3}}{M_{s} \rho_{\mathrm{w}}\left(D_{\mathrm{m}}^{3}-D_{\mathrm{m}, s}^{3}\right)}=\frac{\rho_{s}}{M_{s} \rho_{\mathrm{w}}\left(g_{\mathrm{m}, s}^{3}-1\right)}$.

$m_{s}$ and $m_{\mathrm{w}}$ are the masses of solute and water contained in the droplet, respectively. Combination of Eqs. (1), (6), and (8) leads to a simplified version of the Köhler equation:

$S_{\mathrm{w}}=\exp \left(\frac{4 \sigma M_{\mathrm{w}}}{\rho R T D_{\mathrm{m}}}-\frac{v_{s} \Phi_{s} M_{\mathrm{w}} \rho_{s}}{M_{s} \rho_{\mathrm{w}}\left(g_{\mathrm{m}, s}^{3}-1\right)}\right)$.

Based on the molar volumes of dry solute and pure water, $V_{s}=M_{s} / \rho_{s}$ and $V_{\mathrm{w}}=M_{\mathrm{w}} / \rho_{\mathrm{w}}$, respectively, the activity of water in the droplet can be approximated by

$\ln a_{\mathrm{w}}=-\frac{v_{s} \Phi_{s}}{\left(g_{\mathrm{m}, s}^{3}-1\right)} \frac{V_{\mathrm{w}}}{V_{s}}$.

VA model calculations can be performed with the above equations and the parameterisations for water activity and osmotic coefficients presented in the preceding section or on simplified parameterisations, which are also based on the assumption of volume additivity.

\subsubsection{Simplified ion-interaction parameterisation of $\Phi_{s}$}

Brechtel and Kreidenweis (2000) presented a simplified ion-interaction parameterisation of $\Phi_{s}$ based on H-TDMA experiments. For the experimental conditions of their H-TDMA experiments $\left(80 \%<R H<95 \%\right.$ and $\mu_{s}=1-$ $6 \mathrm{~mol} \mathrm{~kg}^{-1}$ ), they demonstrated that the parameterisation of $\Phi_{s}$ by Pitzer and Mayorga (1973), Eq. (7), can be reduced to

$\Phi_{s}=1-\left|z_{1} z_{2}\right|\left(A_{\Phi} \frac{\sqrt{I}}{1+b_{\mathrm{pit}} \sqrt{I}}\right)+\mu_{s} \frac{2 v_{1} v_{2}}{v_{s}} \beta_{0}$. 

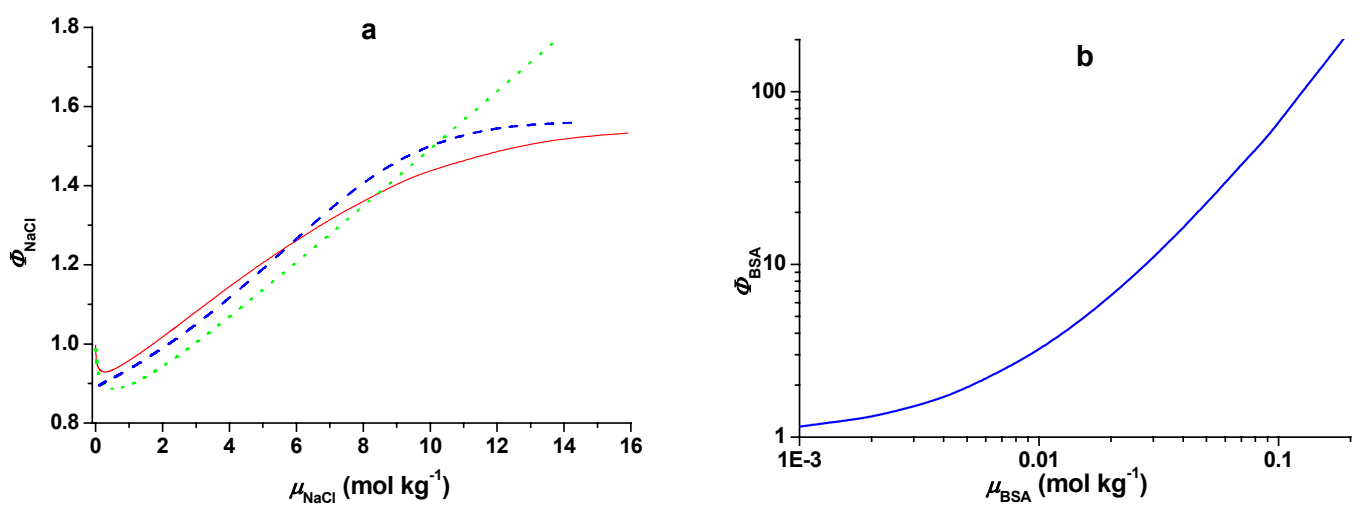

Fig. 2. Molal or practical osmotic coefficient of sodium chloride (a) and bovine serum albumin (b) in aqueous solution plotted against solute molality and calculated from different parameterisations. NaCl: Mokbel et al. (1997), red solid; Tang (1996), blue dashed; Brechtel and Kreidenweis (2000), green dotted. BSA: osmotic pressure parameterisation based on Carnahan and Starling (1969).

Furthermore, they defined a coefficient

$c=\frac{1}{\rho_{\mathrm{w}}\left(g_{\mathrm{m}, s}^{3}-1\right)}$,

which can be calculated from H-TDMA measurement data under the assumption that the mass equivalent growth factor equals the measured mobility equivalent growth factor $\left(g_{\mathrm{m}, s}=g_{\mathrm{b}, s}\right)$. From Eqs. (12) and (8) follows $\mu_{s}=\rho_{s} c / M_{s}$, and combination with the above expression for molal ionic strength leads to a simplified version of Eq. (7):

$\Phi_{s}=1-\frac{A_{\Phi} c^{1 / 2} Y_{\mathrm{f}}^{1 / 2}}{\sqrt{2}+b_{\mathrm{pit}} c^{1 / 2} Y_{\mathrm{f}}^{1 / 2}}+2 c \beta_{0, \mathrm{f}} Y_{\mathrm{f}}$.

$\beta_{0, \mathrm{f}}$ and $Y_{\mathrm{f}}$ are the only two parameters in Eq. (13) which depend on chemical composition of the dry solute particle. Brechtel and Kreidenweis (2000) determined these parameters for several salts by inserting Eq. (13) in Eq. (9), and fitting to H-TDMA measurement data in the range of $80 \%<R H<92 \%$. The reported fit values are $\beta_{0, \mathrm{f}}=0.018 \mathrm{~kg} \mathrm{~mol}^{-1}$ and $Y_{\mathrm{f}}=77.4 \times 10^{-3} \mathrm{~mol} \mathrm{~m}^{-3}$ for $\mathrm{NaCl}$, and $\beta_{0, \mathrm{f}}=-0.004 \mathrm{~kg} \mathrm{~mol}^{-1}$ and $Y_{\mathrm{f}}=44.1 \times 10^{-3} \mathrm{~mol} \mathrm{~m}^{-3}$ for $\mathrm{NH}_{4} \mathrm{NO}_{3}$.

Brechtel and Kreidenweis (2000) have also tested the sensitivity of Köhler model calculations on the simplifying assumptions made above. For $\mathrm{NaCl}, \mathrm{NH}_{4} \mathrm{NO}_{3},\left(\mathrm{NH}_{4}\right)_{2} \mathrm{SO}_{4}$, and several salt mixtures (average solute model, see below), they found that for $R H>75 \%$ the errors arising from the volume additivity assumption and simplified parameterisation of $\Phi_{s}$ were hardly larger than the uncertainties of more detailed modeling approaches and the measurement uncertainties of experimental investigations.

Figure 2a illustrates that for $\mathrm{NaCl}$ the differences between the full semi-empirical parameterisation (Eq. (7); Mokbel et al., 1997) and the simplified semi-empirical parameterisation (Eq. (13); Brechtel and Kreidenweis, 2000) exceed 10\% only at high supersaturation $\left(\mu_{\mathrm{NaCl}}>10 \mathrm{~mol} \mathrm{~kg}^{-1}\right)$.
For VA model calculations based on the simplified semi-empirical parameterisation of $\Phi_{s}, g_{\mathrm{m}, s}$ was taken as the primary variable. Equations (12) and (13) were used to calculate $\Phi_{s}$, and $D_{\mathrm{m}}$ was obtained by inserting $g_{\mathrm{m}, s}$ and $D_{\mathrm{m}, s}$ in Eq. (2). Finally $D_{\mathrm{m}}, \Phi_{s}, v_{s}, M_{\mathrm{w}}, \sigma=\sigma_{\mathrm{w}}$, and $\rho=\rho_{\mathrm{w}}$ were inserted in Eq. (9) to calculate the corresponding equilibrium value of $R H$.

\subsubsection{Osmotic pressure parameterisation of $\Phi_{s}$}

For solute molecules which can be regarded as rigid spheres, Carnahan and Starling (1969) derived the following virial equation of osmotic pressure, $P_{\mathrm{os}}$ :

$$
P_{\mathrm{os}}=\frac{R T \phi_{s}}{V_{s}} \frac{1+\phi_{s}+\phi_{s}^{2}-\phi_{s}^{3}}{\left(1-\phi_{s}\right)^{3}} .
$$

$\phi_{s}$ is the volume fraction of the solute in the solution. Osmotic pressure and water activity of aqueous solutions are related by the basic equation (Atkins, 1982):

$\ln a_{\mathrm{w}}=-\frac{V_{\mathrm{w}}}{R T} P_{\mathrm{os}}$.

Substituting Eq. (14) into (15) we obtain

$\ln a_{\mathrm{w}}=-\frac{V_{\mathrm{w}}}{V_{s}} \frac{\phi_{s}\left(1+\phi_{s}+\phi_{s}^{2}-\phi_{s}^{3}\right)}{\left(1-\phi_{s}\right)^{3}}$.

From the volume additivity assumption follows $\phi_{s}=g_{\mathrm{m}, s}^{-3}$, and with $v_{s}=1$ Eq. (10) can be transformed into

$\ln a_{\mathrm{w}}=-\frac{\Phi_{s}}{\left(1 / \phi_{s}-1\right)} \frac{V_{\mathrm{w}}}{V_{s}}$.

Combination of (16) and (17) yields

$\Phi_{s}=\left(\frac{1}{\phi_{s}}-1\right) \frac{\phi_{s}\left(1+\phi_{s}+\phi_{s}^{2}-\phi_{s}^{3}\right)}{\left(1-\phi_{s}\right)^{3}}=1+\frac{\phi_{s}\left(3-\phi_{s}^{2}\right)}{\left(1-\phi_{s}\right)^{2}}$, 
and by inserting $\phi_{s}=g_{\mathrm{m}, s}^{-3}$ we obtain

$\Phi_{s}=1+\frac{g_{\mathrm{m}, s}^{-3}\left(3-g_{\mathrm{m}, s}^{-6}\right)}{\left(1-g_{\mathrm{m}, s}^{-3}\right)^{2}}$.

Figure $2 \mathrm{~b}$ shows the molal osmotic coefficient of BSA, $\Phi_{\mathrm{BSA}}$, calculated from Eq. (8) and (19) as a function of $\mu_{\mathrm{BSA}}$. $\Phi_{\mathrm{BSA}}$ increases from a lower limit of 1 at low molalities (ideal dilute solution) to values of 100 and more at $\mu_{\mathrm{BSA}}>0.1$, which reflects the high molar volume of the protein.

3.1.2.3 Average solute volume additivity (AS-VA) model for multi-component particles

In order to apply Eq. (9) for aerosol particles and aqueous droplets containing multiple solute components, the solute mixture has to be regarded as a single compound ("average solute"). This approach has been used to model the hygroscopic growth of particles composed of inorganic salt mixtures, and effective values of $M_{s}, \rho_{s}$, and $v_{s} \Phi_{s}$, have been obtained by weighted averaging of the properties of the individual solute components (Pruppacher and Klett, 1997):

$$
\begin{aligned}
& M_{s}=\sum_{y} X_{s, y} M_{y}, \\
& \rho_{s}=\left(\sum_{y} \frac{x_{s, y}}{\rho_{y}}\right)^{-1}, \\
& v_{s} \Phi_{s}=\frac{\sum_{y} v_{y} \Phi_{y} \mu_{y}}{\sum_{y} \mu_{y}} .
\end{aligned}
$$

$X_{s, y}$ and $x_{s, y}$ are the mole and mass fractions of component $y$ in the dry solute particle; $M_{y}, v_{y}, \rho_{y}$ are the molar mass, stoichiometric dissociation number, and density of the pure component, respectively. $\mu_{y}$ is the molality of component $y$ in the mixed aqueous solution droplet, and $\Phi_{y}$ is the osmotic coefficient of a reference aqueous solution which contains component $y$ with the same molality as the mixed solution droplet, $\mu_{y}$, but as the only solute.

For model calculations it is convenient to express $X_{s, y}$ and $\mu_{y}$ in terms of $x_{s, y}$ :

$$
\begin{aligned}
& X_{s, y}=\frac{x_{s, y} / M_{y}}{\sum_{y}\left(x_{s, y} / M_{y}\right)}, \\
& \mu_{y}=\frac{m_{y}}{M_{y} m_{\mathrm{w}}}=\frac{\rho_{s} x_{s, y}}{M_{y} \rho_{\mathrm{w}}\left(g_{\mathrm{m}, s}^{3}-1\right)} .
\end{aligned}
$$

In the AS-VA model calculations for mixed protein-salt particles presented below, $g_{\mathrm{m}, \mathrm{s}}$ and $x_{s, y}$ were taken as the primary input variables. Equations (20), (21), and (23) were applied to calculate $M_{s}$ and $\rho_{s}$, respectively. $\mu_{y}$ and $\Phi_{y}$ were calculated for every individual component based on Eq. (24) and on the parameterisations presented above for aqueous solutions of pure solutes. $v_{s} \Phi_{s}$ was calculated from Eq. (22), and $D_{\mathrm{m}}$ was obtained by inserting $g_{\mathrm{m}, \mathrm{s}}$ and $D_{\mathrm{m}, s}$ in Eq. (2). Finally, $D_{\mathrm{m}}, v_{s} \Phi_{s}, M_{s}, \rho_{s}, M_{\mathrm{w}}, \sigma=\sigma_{\mathrm{w}}$, and $\rho=\rho_{\mathrm{w}}$ were inserted in Eq. (9) to obtain the corresponding equilibrium value of $R H$.

Obviously, the molalities of the individual components, $\mu_{y}$, have to be inserted for $\mu_{s}$ in the ion-interaction parameterisations presented above to calculate $\Phi_{y}$. To calculate $\Phi_{y}$ from the osomotic pressure parameterisation, an effective growth factor for the individual solute component $g_{\text {eff, } y}$ has to be used instead of the overall mass equivalent growth factor $g_{\mathrm{m}, s}$ in Eq. (19). $g_{\mathrm{eff}, y}$ is the mass equivalent growth factor of a reference aqueous solution droplet which contains component $y$ with the same molality as the mixed solution droplet, $\mu_{y}$, but as the only solute:

$$
\begin{aligned}
& \mu_{y}=\frac{\rho_{y}}{M_{y} \rho_{\mathrm{w}}\left(g_{\text {eff }, y}^{3}-1\right)}, \\
& g_{\text {eff }, y}=\left(\frac{\rho_{y}}{\rho_{s} x_{s, y}}\left(g_{\mathrm{m}, s}^{3}-1\right)+1\right)^{1 / 3} .
\end{aligned}
$$

Based on the volume additivity assumption, $g_{\text {eff, } y}^{3}$ can be regarded as the volume fraction of the pure solute $y$ in the reference solution, and thus $g_{\mathrm{eff}, y}$ can be inserted for $g_{\mathrm{m}, s}$ in Eq. (19) to calculate $\Phi_{y}$.

3.1.2.4 Separate solute volume additivity (SS-VA) model for multi-component particles

Under the assumption that different solute components contained in a multi-component particle do not interact with each other ("separate solutes"), Eq. (1) can be generalised in the form

$S_{\mathrm{w}}=\prod_{y} a_{\mathrm{w}, y} \exp \left(\frac{4 \sigma M_{\mathrm{w}}}{\rho R T D_{\mathrm{m}}}\right)$.

$a_{\mathrm{w}, y}$ is the activity of water in an aqueous solution droplet containing only one specific solute component $y$. Based on the volume additivity assumption and in analogy to the derivation of Eq. (9) from Eq. 1), Eq. (27) can be transformed into

$$
S_{\mathrm{w}}=\exp \left(\frac{4 \sigma M_{\mathrm{w}}}{\rho R T D_{\mathrm{m}}}-\frac{M_{\mathrm{w}}}{\rho_{\mathrm{w}}\left(g_{\mathrm{m}}^{3}-1\right)} \sum_{y} \frac{v_{y} \Phi_{y} \rho_{y} x_{s, y}}{M_{y}}\right) .
$$

The SS-VA model calculations for mixed protein-salt particles presented below were performed in analogy to the ASVA calculations described above (Sect. 3.1.2.3), except that the parameters describing the individual solute components $\left(M_{y}, \rho_{y}, x_{s, y}, \mu_{y}, v_{y} \Phi_{y}\right)$ were not averaged but directly inserted in Eq. (28). 


\subsection{Particle shape factors}

The shape and microstructure of an aerosol particle can be characterised by its dynamic shape factor $\chi$, which is defined as the ratio of the drag force on the particle to the drag force on the particle's mass equivalent sphere at the same velocity (Fuchs, 1964). $\chi$ relates the mobility equivalent diameter of a particle to its mass equivalent diameter (Brockmann and Rader, 1990; Kelly and McMurry, 1992):

$\frac{D_{\mathrm{m}}}{D_{\mathrm{b}}}=\frac{1}{\chi} \frac{C\left(D_{\mathrm{m}}\right)}{C\left(D_{\mathrm{b}}\right)}$,

the slip correction factors $C\left(D_{\mathrm{m}}\right)$ and $C\left(D_{\mathrm{b}}\right)$ can be approximated by the empirical relation

$C(D)=1+\left(\frac{2 \lambda}{D}\right)\left(1.142+0.558 \exp \left(-0.999 \frac{D}{2 \lambda}\right)\right)$,

into which the appropriate particle diameter $D$ and the mean free path of the gas molecules $\lambda$ are inserted $(\lambda \approx 70 \mathrm{~nm}$ for nitrogen at $298 \mathrm{~K}$ and $960 \mathrm{hPa}$; Allen and Raabe, 1985; Willeke and Baron, 1993).

For compact spherical and cubic particles the dynamic shape factors are $\chi_{\text {sphere }}=1.00$ and $\chi_{\text {cube }}=1.08$, respectively. For agglomerates and irregularly shaped particles $\chi$ increases to values of 2 and more (Hinds, 1999; Brockmann and Rader, 1990; Willeke and Baron, 1993; Krämer et al., 2001). $\chi$ can be split into a component $\kappa$ which describes the shape of the particle envelope and a component $\delta$ which is related to the particle porosity and allows the calculation of the void fraction inside the particle envelope, $f$ (Brockmann and Rader, 1990):

$\chi=\kappa \delta \frac{C\left(D_{\mathrm{m}}\right)}{C\left(\delta D_{\mathrm{m}}\right)}$,

$f=\left(1-\delta^{-3}\right)$.

\section{Results and discussion}

4.1 Pure sodium chloride particles

\subsubsection{Hygroscopic growth}

The experimental results obtained for pure $\mathrm{NaCl}$ particles with $D_{\mathrm{b}, \mathrm{i}}=99 \mathrm{~nm}$ in H-TDMA modes 1 (hydration) and 2 (dehydration) are summarised in Table 3 and illustrated in Fig. 3, which shows the measured particle diameter plotted against relative humidity. Upon hydration, the deliquescence transition, i.e. the transformation of the solid salt particle into a saturated solution droplet, was observed at $R H_{\mathrm{d}}=(75 \pm 2) \%$, which is in good agreement with theoretical predictions $\left(R H_{\mathrm{d}}=75.3 \%\right.$; Tang and Munkelwitz, 1993) and experimental literature data (Tang et al., 1977; Krämer et al., 2000; Gysel et al., 2002). At $R H<R H_{\mathrm{d}}$ the measured

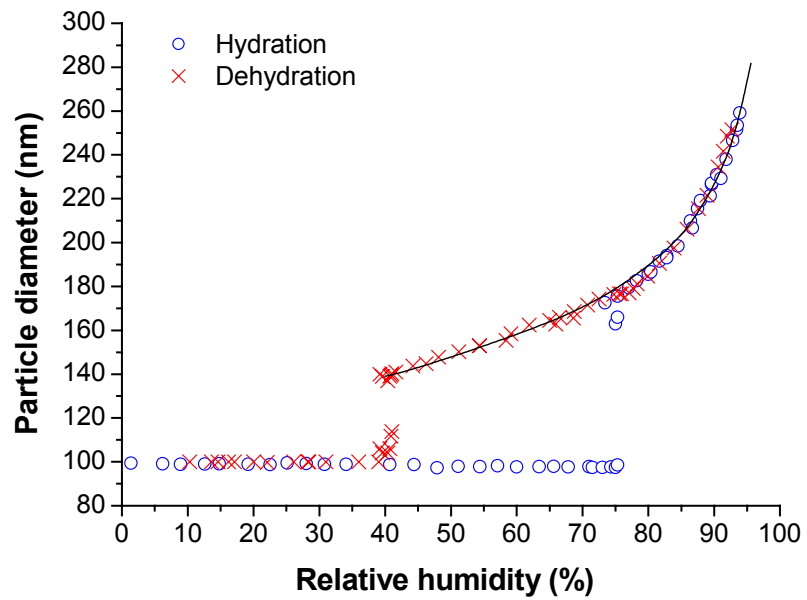

Fig. 3. Mobility equivalent diameters of $\mathrm{NaCl}$ particles with $D_{\mathrm{b}, \mathrm{i}}=99 \mathrm{~nm}$ observed upon hydration (H-TDMA mode 1) and dehydration (H-TDMA mode 2) compared to Köhler theory calculations with the FP model based on $\Phi_{\mathrm{NaCl}}$ from Mokbel (1997), $\rho$ from Tang (1996), and $D_{\mathrm{m}, s}=95 \mathrm{~nm}$.

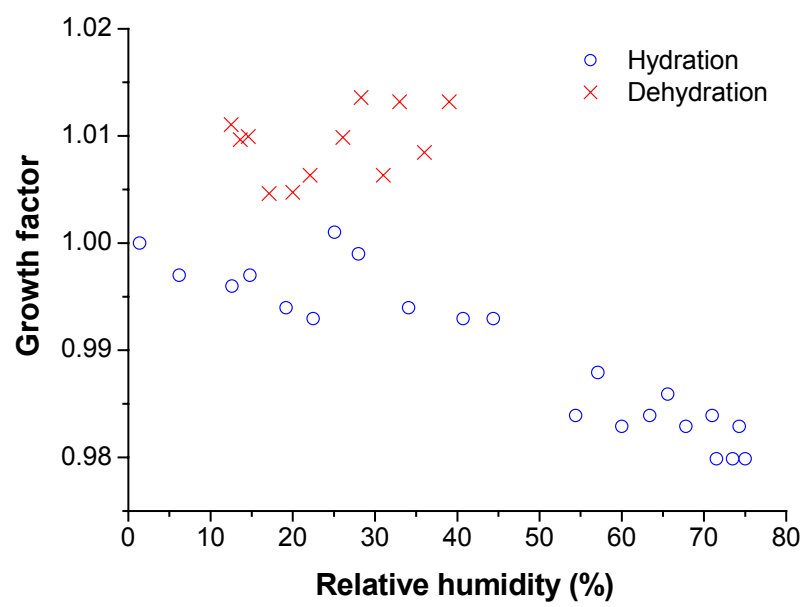

Fig. 4. Mobility equivalent growth factors, $g_{\mathrm{b}}=D_{\mathrm{b}} / D_{\mathrm{b}, \mathrm{i}}$, of nondeliquesced $\mathrm{NaCl}$ particles with $D_{\mathrm{b}, \mathrm{i}}=99 \mathrm{~nm}$ observed upon hydration $\left(R H<R H_{\mathrm{d}}\right)$ and dehydration $\left(R H<R H_{\mathrm{e}}\right)$.

mobility equivalent diameters exhibited a slight decrease towards the deliquescence threshold, where a minimum value $D_{\mathrm{b}, \mathrm{hy}, \min }=97 \mathrm{~nm}$ was observed (average value for $60-75 \%$ $R H$; see also Fig. 4). At $R H>R H_{\mathrm{d}}$ the measured diameters agree very well with Köhler theory calculations performed with the FP model based on $\Phi_{\mathrm{NaCl}}$ from Mokbel et al. (1997), on $\rho$ from Tang (1996), and on the assumption $D_{\mathrm{m}, s}=D_{\mathrm{b}, \mathrm{hy}, \mathrm{min}, \mathrm{hlcorr}}=95 \mathrm{~nm}$, which will be discussed below.

The hysteresis branch measured upon dehydration is due to the existence of solution droplets in a metastable state of $\mathrm{NaCl}$ supersaturation $\left(R H_{\mathrm{e}}<R H<R H_{\mathrm{d}}\right)$. The efflorescence transition, i.e. the formation of a salt crystal and evaporation 
Table 3. Phase transition and microstructural rearrangement parameters for pure $\mathrm{NaCl}$ particles and mixed NaCl-BSA particles with initial diameter $D_{\mathrm{b}, \mathrm{i}}=99 \mathrm{~nm} . R H_{\mathrm{d}}$ and $R H_{\mathrm{e}}$ are the relative humidities at which deliquescence and efflorescence were observed, respectively. $\Delta_{\mathrm{r}, \mathrm{d}} D_{\mathrm{b}}$ and $\Delta_{\mathrm{r}, \mathrm{e}} D_{\mathrm{b}}$ are the relative changes of mobility equivalent diameter upon deliquescence and efflorescence, respectively, referring to the diameters measured just before and after the phase transition. $g_{\text {hy, } \min }$ and $g_{\text {de,min }}$ are the minimum mobility equivalent growth factors observed upon hydration and dehydration, respectively. The measurement precision was generally better than $\pm 2 \%$ for $R H$ and $\pm 1 \%$ for $D_{\mathrm{b}}$.

\begin{tabular}{ccccccc}
\hline $\begin{array}{c}\text { BSA Dry Mass } \\
\text { Fraction (\%) }\end{array}$ & $\begin{array}{c}R H_{\mathrm{d}} \\
(\%)\end{array}$ & $\begin{array}{c}R H_{\mathrm{e}} \\
(\%)\end{array}$ & $\begin{array}{c}\Delta_{\mathrm{r}, \mathrm{d}} D_{\mathrm{b}} \\
(\%)\end{array}$ & $\begin{array}{c}\Delta_{\mathrm{r}, \mathrm{e}} D_{\mathrm{b}} \\
(\%)\end{array}$ & $g_{\mathrm{b}, \text { hy }, \text { min }}$ & $g_{\mathrm{b}, \text { de, min }}$ \\
\hline 0 & 75 & 41 & 76 & -29 & 0.98 & 1.01 \\
10 & 75 & 40 & 69 & -29 & 0.93 & 0.94 \\
25 & 73 & 38 & 89 & -18 & 0.86 & 0.91 \\
50 & 74 & 37 & 36 & -13 & 0.89 & 0.88 \\
50 & 74 & 37 & 34 & -13 & 0.91 & 0.90 \\
75 & 75 & 36 & 7 & -6 & 0.97 & 0.84 \\
90 & & & & & & 0.94 \\
\hline
\end{tabular}

*Neutralisation mode B

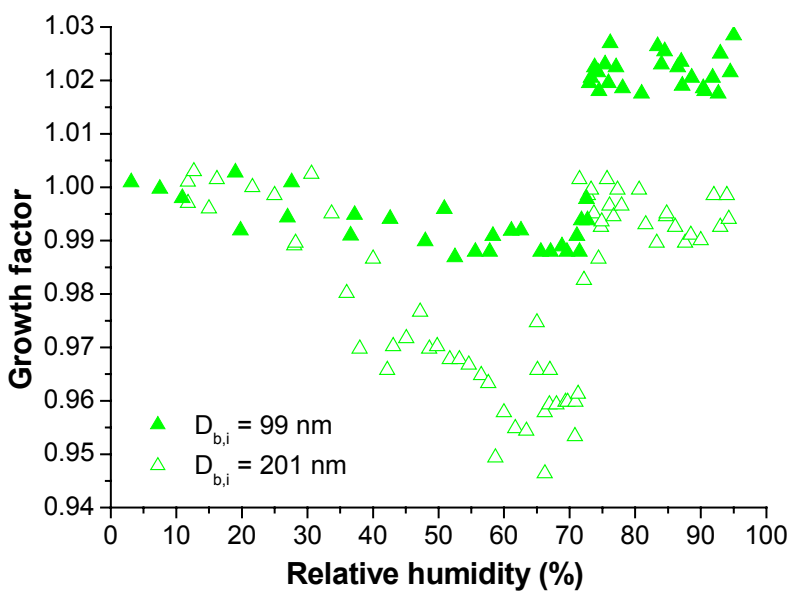

Fig. 5. Mobility equivalent growth factors of $\mathrm{NaCl}$ particles with $D_{\mathrm{b}, \mathrm{i}}=99 \mathrm{~nm}$ and $D_{\mathrm{b}, \mathrm{i}}=201 \mathrm{~nm}$ observed upon hydration \& dehydration (H-TDMA mode 3, $\mathrm{RH}_{2}$ ).

of the liquid water content, was observed at $R H_{\mathrm{e}}=(41 \pm 2) \%$. This is at the lower end of the range of efflorescence relative humidities reported in the literature, $37 \%<R H_{\mathrm{e}}<50 \%$ (Martin, 2000; Tang, 2000; Krieger and Braun, 2001; and references therein). Higher values are generally attributed to heterogeneous nucleation on impurities (Lightstone et al., 2000; Tang, 2000). After efflorescence $\left(R H<R H_{\mathrm{e}}\right)$, the mobility equivalent diameters measured upon dehydration were slightly larger than the initial diameter.

Figure 4 displays the mobility equivalent growth factors, $g_{\mathrm{b}}=D_{\mathrm{b}} / D_{\mathrm{b}, \mathrm{i}}$, calculated from the diameter measurement data displayed in Fig. 3 for the non-deliquesced particles upon hydration $\left(R H<R H_{\mathrm{d}}\right)$ and dehydration $\left(R H<R H_{\mathrm{e}}\right)$. Their deviations from unity exceed the usual scatter related to diameter measurement precision $( \pm 1 \%)$ and can be attributed to microstructural rearrangement processes, as detailed below.

\subsubsection{Microstructural rearrangement}

Figure 5 illustrates the results obtained for pure $\mathrm{NaCl}$ particles with $D_{\mathrm{b}, \mathrm{i}}=99 \mathrm{~nm}$ and $D_{\mathrm{b}, \mathrm{i}}=201 \mathrm{~nm}$ in H-TDMA mode 3 (hydration \& dehydration), where the relative humidity was varied only in the conditioner tube $\left(\mathrm{RH}_{2}\right)$ whereas DMA 2 was used not only as a particle sizer but also as a dryer $\left(R H_{3}=0, R H_{4}<10 \%\right)$. At $R H_{2}<R H_{\mathrm{d}}$ the particles with $D_{\mathrm{b}, \mathrm{i}}=99 \mathrm{~nm}$ exhibited essentially the same small mobility equivalent diameter reduction as observed in operation mode 1 , and the mobility equivalent growth factor, $g_{\mathrm{b}, \mathrm{h} \& \mathrm{~d}}=D_{\mathrm{b}, \mathrm{h} \& \mathrm{~d}} / D_{\mathrm{b}, \mathrm{i}}$, decreased towards the deliquescence threshold, where an average minimum value

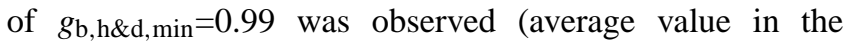
$R H$ range of $60-73 \%)$. At the deliquescence threshold $\left(R H_{\mathrm{d}}=75 \%\right), g_{\mathrm{b}, \mathrm{h} \& \mathrm{~d}}$ showed a step-wise increase to a nearconstant value of 1.02 , i.e. a reproducible $3 \%$ increase of the dry particle mobility equivalent diameter occurred after deliquescence in the conditioner tube and efflorescence in DMA $2\left(R_{2}>R H_{d}\right)$. Similar but more pronounced effects were observed for the larger particles with $D_{\mathrm{b}, \mathrm{i}}=201 \mathrm{~nm}$. For these particles $g_{b \text {,h\&d }}$ was near unity up to $R H_{2} \approx 30 \%$ and exhibited a near-linear decrease in the humidity range of $30-55 \%$ and an average minimum value of $g_{\mathrm{b}, \mathrm{h} \& \mathrm{~d}, \min }=0.96$ at $55 \%<R H_{2}<R H_{\mathrm{d}}$. After a stepwise increase by $4 \%$ the growth factor observed at $R H_{2}>R H_{\mathrm{d}}$ was close to unity again.

The different morphologies and microstructures reported for $\mathrm{NaCl}$ aerosol particles range from solid spheres or cubes to fractal agglomerates, depending on the aerosol generation method and conditioning or physical aging of the 
investigated aerosol (Krämer et al., 2000; and references therein). Assuming that the mass equivalent diameter $D_{\mathrm{m}}$ is practically constant for $\mathrm{NaCl}$ salt particles at $R H<R H_{\mathrm{e}}$, Eq. (29) can be rewritten as

$\frac{D_{\mathrm{b}, j}}{D_{\mathrm{b}, k}}=\frac{\chi_{j}}{\chi_{k}} \frac{C\left(D_{\mathrm{b}, j}\right)}{C\left(D_{\mathrm{b}, k}\right)}=\frac{g_{\mathrm{b}, j}}{g_{\mathrm{b}, k}}$,

where $D_{\mathrm{b}, j}, D_{\mathrm{b}, k}, g_{\mathrm{b}, j}$, and $g_{\mathrm{b}, k}$ stand for the mobility equivalent diameters and growth factors of the investigated particles observed in two arbitrary microstructural states $j$ and $k$, respectively. Inserting the experimental data in Eq. (29) and (30) yields $\chi_{\mathrm{h} \& \mathrm{~d}, \mathrm{e}} / \chi_{\mathrm{h} \& \mathrm{~d}, \min }=1.06$ for $D_{\mathrm{b}, \mathrm{i}}=99 \mathrm{~nm}$ and $\chi_{\mathrm{h} \& \mathrm{~d}, \mathrm{e}} / \chi_{\mathrm{h} \& \mathrm{~d}, \min }=\chi_{\mathrm{i}} / \chi_{\mathrm{h} \& \mathrm{~d}, \min }=1.07$ for $D_{\mathrm{b}, \mathrm{i}}=201 \mathrm{~nm}$, which is close to the theoretical value of $\chi_{\text {cube }} / \chi_{\text {sphere }}=1.08 . \chi_{i}$, $\chi_{\mathrm{h} \& \mathrm{~d}, \min }$ and $\chi_{\mathrm{h} \& \mathrm{~d}, \mathrm{e}}$ are the shape factors of the initially selected particles, the minimum diameter particles, and the effloresced particles observed in H-TDMA mode 3 (hydration \& dehydration, $\mathrm{RH}_{2}>\mathrm{R} \mathrm{H}_{\mathrm{d}}$ ), respectively.

The simplest possible explanation for the above results is that the $\mathrm{NaCl}$ particles with $D_{\mathrm{b}, \mathrm{i}}=99 \mathrm{~nm}$ selected by DMA 1 had an irregular shape $\left(\chi_{\text {sphere }}<\chi_{i}<\chi_{\text {cube }}\right)$, underwent transformation to near-spherical shape upon interaction with water vapor up to the deliquescence threshold $\left(R H_{2}<R H_{\mathrm{d}}\right)$, and recrystallisation to near-cubic shape upon efflorescence in DMA $2\left(R H_{2}>R H_{\mathrm{d}}\right)$. The particles with $D_{\mathrm{b}, \mathrm{i}}=201 \mathrm{~nm}$, on the other hand, seem to have undergone a transformation from initial near-cubic shape $\left(\mathrm{RH}_{2}<30 \%\right)$ to near-spherical shape $\left(60 \%<R H_{2}<R H_{\mathrm{d}}\right)$ and back to near-cubic shape upon efflorescence in DMA $2\left(R H_{2}>R H_{\mathrm{d}}\right)$.

The irregular initial shape of the aerosol particles with $D_{\mathrm{b}, \mathrm{i}}=99 \mathrm{~nm}$, the near-cubic initial shape of the aerosol particles with $D_{\mathrm{b}, \mathrm{i}}=201 \mathrm{~nm}$, and their transformation from nearcubic to near-spherical shape upon interaction with water vapor at $R H<R H_{\mathrm{d}}$ were confirmed by transmission electron microscopy (TEM) of deposited particles, which have been prepared as described in Sect. 2. Figure 6 (A1) shows $\mathrm{NaCl}$ particles sampled at the output of the SDD with $R H \approx 35 \%$. The larger particles with diameters near $200 \mathrm{~nm}$ exhibit nearcubic shape, whereas the smaller particles with diameters near $100 \mathrm{~nm}$ exhibit irregular shapes. Figure 6A2 shows $\mathrm{NaCl}$ particles after humidification $(\mathrm{RH} \approx 70 \%, 20 \mathrm{~s})$. In this case only a large particle with a diameter of $\sim 500 \mathrm{~nm}$ exhibits near-cubic shape with rounded corners, but all smaller particles exhibit near-spherical shape.

Overall, the observations can be interpreted by the following hypotheses:

1. $\mathrm{NaCl}$ aerosol particles in the $100-200 \mathrm{~nm}$ size range freshly formed by efflorescence of aqueous $\mathrm{NaCl}$ solution droplets are of (near-)cubic shape.

2. Upon interaction with water vapor at $R H<R H_{\mathrm{d}}$, surface adsorbed water partially dissolves the salt surface - preferentially at the corners and edges of the crystals - and thus transforms the near-cubic into near-spherical particles.
3. The microstructural rearrangement by partial dissolution of the crystal surface upon interaction with water vapor is kinetically limited (interaction time and relative humidity).

Hypothesis 1 explains why the hydration \& dehydration experiments indicate near-cubic shape for both the particles with $D_{\mathrm{b}, \mathrm{i}}=99 \mathrm{~nm}$ and those with $D_{\mathrm{b}, \mathrm{i}}=201 \mathrm{~nm}$ after efflorescence in DMA 2, regardless of their microstructure before deliquescence in the conditioner tube. Hypothesis 2 explains the transformation from near-cubic or irregular to near-spherical shape at $R H<R H_{\mathrm{d}}$. Hypothesis 3 explains the observed differences between $100 \mathrm{~nm}$ and $200 \mathrm{~nm}$ particles and between particle drying in the SDD and in DMA 2 operated in H-TDMA modes 2 and 3.

In the SDD (residence time $\sim 10 \mathrm{~s}$ ) the relative humidity of the freshly generated aerosol flow was decreased from $\sim 100 \%$ in the nebuliser to $\sim 38 \%$, i.e. just below the experimental value of $R H_{\mathrm{e}}$. Thus the solid particles formed upon efflorescence could interact with water vapor at $R H \approx 38 \%$ in the tubing and neutraliser between the SDD and DMA 1 (residence time $\sim 10 \mathrm{~s}$ ), before they were further dried by the dry nitrogen sheath gas and size selected. Apparently this relative humidity and interaction time were sufficient to convert the $100 \mathrm{~nm}$ salt particles to near-spherical shape. For the $200 \mathrm{~nm}$ salt particles, however, higher relative humidities were required to reach near-spherical shape: $R H>55 \%$ in the conditioner tube (residence time $\sim 11 \mathrm{~s}$ ).

In DMA 2 operated in H-TDMA mode 3, particle drying proceeded much faster and more efficient than in the SDD. By addition of the dry nitrogen sheath gas the relative humidity was effectively decreased by a factor of ten within a couple of seconds (flow channel width between outer steel cylinder and central electrode of DMA 2: $1.07 \mathrm{~cm}$; root mean square distance of diffusion of $\mathrm{H}_{2} \mathrm{O}$ in air within $1 \mathrm{~s}$ at standard temperature and pressure: $\sim 0.6 \mathrm{~cm}$ (Atkins, 1982). The resulting relative humidities of $<10 \%$ experienced by the particles after efflorescence in DMA 2 (residence time $7.5 \mathrm{~s}$ ) were apparently too low to transform them from near-cubic to near-spherical shape.

These humidity differences and the postulated kinetic limitation can explain why the particles with $D_{\mathrm{b}, \mathrm{i}}=99 \mathrm{~nm}$ exhibited a stronger increase of mobility equivalent diameter after efflorescence in H-TDMA mode 3 (Fig. 5; $g_{\mathrm{b}, \mathrm{h} \& \mathrm{~d}, \mathrm{e}}=1.02$; $\left.R H_{2}>R H_{\mathrm{d}}, R H_{3}=0, R H_{4}<10 \%\right)$ than after efflorescence in H-TDMA mode 2 (Fig. $4 ; g_{\mathrm{b}, \mathrm{h} \& \mathrm{~d}, \mathrm{e}}=1.01 ; R H_{2}>R H_{\mathrm{d}}$, $\left.R H_{3} \approx R H_{4}<R H_{\mathrm{e}}\right)$. The fact that the hydration \& dehydration experiments indicate a gradual transformation of the particles with $D_{\mathrm{b}, \mathrm{i}}=201 \mathrm{~nm}$ from near-cubic to near-spherical shape upon interaction with water vapor at $30 \%<R H<R H_{\mathrm{d}}$ in the conditioner tube (interaction time $\sim 11 \mathrm{~s}$ ) but not in DMA 2 (decrease of $R H$ from $>R H_{\mathrm{d}}$ to $\sim 10 \%$ within $\sim 1 \mathrm{~s}$ ) also supports a kinetic limitation of the microstructural rearrangement process. 

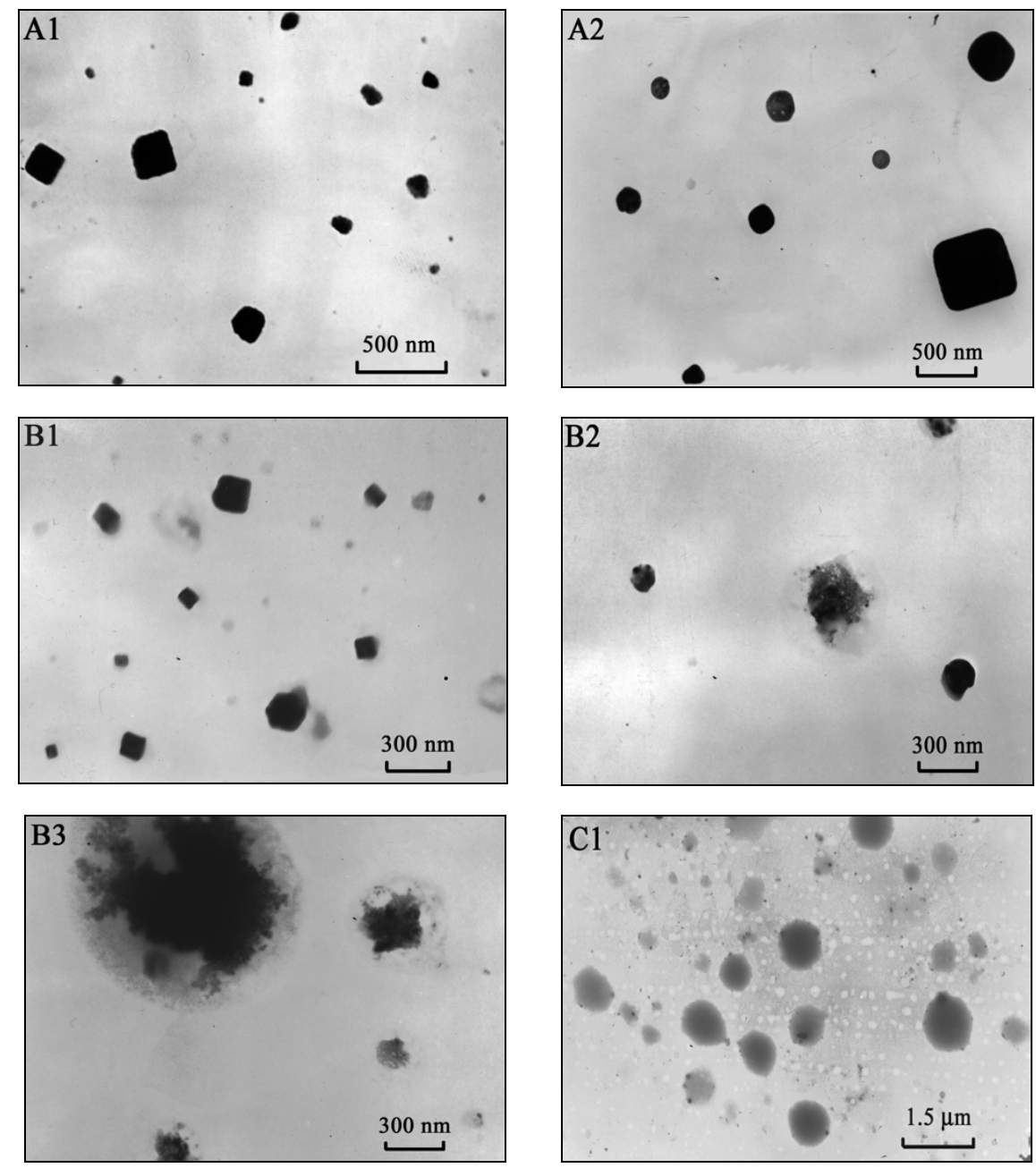

Fig. 6. TEM micrographs of deposited aerosol particles composed of sodium chloride ( $\mathrm{NaCl}$, high contrast) and bovine serum albumin (BSA, low contrast): pure $\mathrm{NaCl}$ particles before conditioning (A1) and after conditioning at $R H=70 \%$ (A2); mixed $\mathrm{BSA}-\mathrm{NaCl}$ particles with $\mathrm{BSA}$ dry solute mass fractions of $25 \%$ (B1) and $50 \%$ (B2, B3); pure BSA particles (C1).

Moreover, the postulated kinetic limitation is in agreement with the results of Weis and Ewing (1999), who investigated the interaction of water vapor with $\mathrm{NaCl}$ aerosol particles with a median diameter of $0.4 \mu \mathrm{m}$ by optical spectroscopy. They found that equilibration at $R H=12-44 \%$ was reached after 3-6s, i.e. the same timescale of the H-TDMA experiments.

On the other hand, the apparent kinetic limitation does not exclude additional thermodynamic limitations, which might govern the maximum extent of conversion from near-cubic to near-spherical shape that can be reached at a given relative humidity. Additional experiments with varying interaction times will be required to find out whether the intermediate stages of restructuring observed for the particles with $D_{\mathrm{b}, \mathrm{i}}=201 \mathrm{~nm}$ at $R H_{2}<R H_{\mathrm{d}}$ in H-TDMA mode 3 are thermodynamically stable, or if all particles would be converted to near-spherical shape after sufficiently long interaction times.
Another aspect to be investigated in further experiments is the potential influence of electric charges on the involved processes (Pruppacher and Klett, 1997; Brodskaya et al., 2002). In this study all experiments reported for pure $\mathrm{NaCl}$ particles were performed in neutralisation mode A, i.e. the drying process in the SDD took place before the particles were neutralised and size selected. Thus the particles which carried one elementary charge upon size-selection in DMA 1 and determined the initial mobility equivalent diameter $D_{\mathrm{b}, \mathrm{i}}$ might have carried more than just one elementary charge upon efflorescence and crystallisation in the SDD. The particles measured after hydration and dehydration in H-TDMA mode 3, however, can be assumed to have carried only one elementary charge upon efflorescence and crystallisation in DMA 2. Consequently different states of electrical charging may have contributed to the observed differences between particle drying in the SDD and in DMA 2. On the other hand, 
electrical charge effects are neither required to explain the observations, nor do they appear to be sufficient to replace one of the effects and processes postulated in hypotheses 13. Therefore we suppose that charging effects might limit or modify but hardly overthrow hypotheses $1-3$.

Microstructural rearrangements of $\mathrm{NaCl}$ aerosol particles in H-TDMA experiments at $R H<R H_{\mathrm{d}}$ have been reported in a couple of earlier studies. Krämer et al. (2000) found that the mobility equivalent diameter of dry $\mathrm{NaCl}$ hightemperature condensation aerosol particles in the $20-100 \mathrm{~nm}$ size range decreased by up to $50 \%$ upon interaction with water vapor at $R H<R H_{\mathrm{d}}$, which they attributed to a transformation of sparse branched-chain to more compact but still porous agglomerates. For $\mathrm{NaCl}$ aerosol particles generated by nebulisation and drying of salt solution droplets Krämer et al. (2000) observed no significant restructuring effects; the results implied a non-porous compact particle structure but allowed no conclusive distinction between near-cubic and near-spherical envelope shape. Gysel et al. (2002), on the other hand, found that the mobility equivalent diameter of $\mathrm{NaCl}$ aerosol particles generated by nebulisation and drying of salt solution droplets decreased by up to $9 \%$ when $R H$ was increased from $20 \%$ to $R H_{\mathrm{d}}$. They attributed these changes to the elimination of initial particle shape irregularities but provided no detailed structural interpretation of their observations.

\subsubsection{Model calculations}

For accurate model calculations of hygroscopic growth, the mass equivalent diameter of the dry solute particles, $D_{\mathrm{m}, s}$, has to be known. The H-TDMA results and TEM pictures described above indicate near-spherical shape for the particles conditioned at relative humidities of $70-75 \%$, which implies that the minimum mobility equivalent diameter values observed under these conditions, $D_{\mathrm{b}, \min }$, should be nearidentical to the mass equivalent diameter of the investigated particles. On the other hand, the observed microstructural rearrangements indicate that significant amounts of water can be adsorbed on the particle surface ("hydration layer"). Foster and Ewing (1999) have investigated the adsorption of water on the surface of $\mathrm{NaCl}(100)$ with infrared spectroscopy, and for $R H \sim 65 \%(303 \mathrm{~K})$ they found that the surface was covered by about 3 monolayers of water, which corresponds to a liquid-like film of about $1 \mathrm{~nm}$ thickness. Thus we have estimated the actual dry solute mass equivalent diameter of the particles with $D_{\mathrm{b}, \mathrm{i}}=99 \mathrm{~nm}$ by subtraction of $2 \mathrm{~nm}$ from the minimum mobility equivalent diameter observed upon hydration, $D_{\mathrm{b}, \text { hy,min }}$ (Figs. 4 and 5): $D_{\mathrm{m}, \mathrm{NaCl}} \approx D_{\mathrm{b}, \mathrm{hy} \text {, min, hlcorr }}=95 \mathrm{~nm}$.

In Fig. 7 the measurement data from the upper branch of the hysteresis curve in Fig. 2 (hydration, dehydration, $R H>40 \%$ ) are compared with calculations using different models and dry solute mass equivalent diameters. The best agreement was achieved with

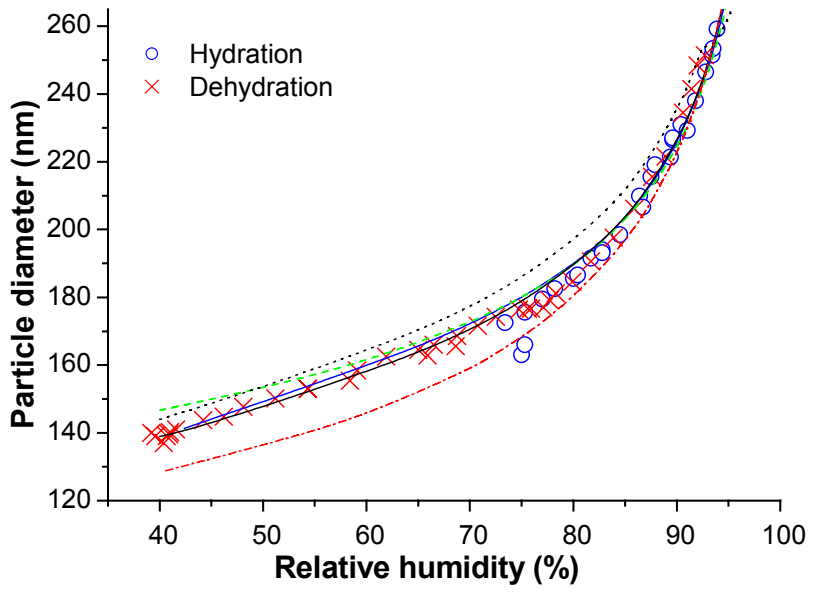

Fig. 7. Mobility equivalent diameters of deliquesced $\mathrm{NaCl}$ particles with $D_{\mathrm{b}, \mathrm{i}}=99 \mathrm{~nm}$ observed upon hydration (H-TDMA mode 1 ) and dehydration (H-TDMA mode 2) compared to Köhler theory calculations with $D_{\mathrm{m}, \mathrm{NaCl}}=D_{\text {hy, min, hlcorr }}=95 \mathrm{~nm}$ (except black dotted line with $D_{\mathrm{m}, \mathrm{NaCl}}=D_{\mathrm{b}, \mathrm{i}}=99 \mathrm{~nm}$ ) and different models: VA with $\Phi_{\mathrm{NaCl}}=1$, red dash-dotted; VA with $\Phi_{\mathrm{NaCl}}$ from Brechtel and Kreidenweis (2000), green dashed; FP with $\Phi_{\mathrm{NaCl}}$ from Mokbel et al. (1997) and $\rho$ from Tang (1996), black solid and dotted; FP with $a_{\mathrm{W}}$ and $\rho$ from Tang (1996), blue solid.

$D_{\mathrm{m}, \mathrm{NaCl}}=D_{\mathrm{b}, \text { hy }, \text { min, hlcorr }}=95 \mathrm{~nm}$ inserted in the FP models based $a_{\mathrm{w}}$ and $\rho$ from Tang (1996) and on $\Phi_{\mathrm{NaCl}}$ from Mokbel et al. (1997) and $\rho$ from Tang (1996), respectively. The diameters calculated with these models generally deviated by less than $\pm 2 \%$ from each other and from the measurement data. Above $R H_{\mathrm{d}}$ also the VA model based on $\Phi_{\mathrm{NaCl}}$ by Brechtel and Kreidenweis (2000) agreed well with the FP models. For supersaturated solution droplets, however, the VA model diameters were systematically higher by up to $+7 \%(R H=40 \%)$, which reflects the deviations of the different parameterisations for $\Phi_{\mathrm{NaCl}}$ at high $\Phi_{\mathrm{NaCl}}$ (Fig. 2a). Accordingly, VA model calculations based on the assumption of near-ideal solute properties with $\Phi_{\mathrm{NaCl}}=1$ were up to $10 \%$ lower than the FP model calculations. The influence of dry solute mass equivalent diameter is illustrated by FP model calculations ( $\Phi_{\mathrm{NaCl}}$ from Mokbel et al. (1997); $\rho$ from Tang (1996)) with $D_{\mathrm{m}, \mathrm{NaCl}}=D_{\mathrm{b}, \mathrm{i}}=99 \mathrm{~nm}$. The resulting diameters are $4 \%$ higher throughout the investigated $R H$ range, and demonstrate that deviations due to incorrect estimation of the dry solute mass equivalent diameter can easily exceed deviations due to different modeling approaches, in particular at high relative humidities.

\subsection{Pure ammonium nitrate particles}

\subsubsection{Hygroscopic growth}

The experimental results obtained for pure $\mathrm{NH}_{4} \mathrm{NO}_{3}$ particles with $D_{\mathrm{b}, \mathrm{i}}=99 \mathrm{~nm}$ in HTDMA modes 1 and 2 are 


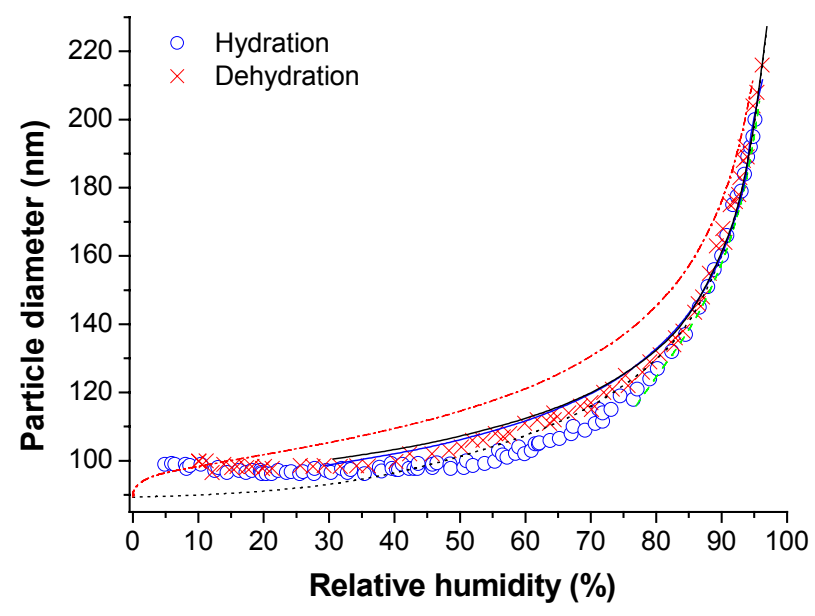

Fig. 8. Mobility equivalent diameters of deliquesced $\mathrm{NH}_{4} \mathrm{NO}_{3}$ particles with $D_{\mathrm{b}, \mathrm{i}}=99 \mathrm{~nm}$ observed upon hydration (H-TDMA mode 1) and dehydration (H-TDMA mode 2) compared to Köhler theory calculations with $D_{\mathrm{m}, \mathrm{NH}_{4} \mathrm{NO}_{3}}=D_{\mathrm{b}, \mathrm{h} \& \mathrm{~d}, \mathrm{~min}}=89 \mathrm{~nm}$ and dif-

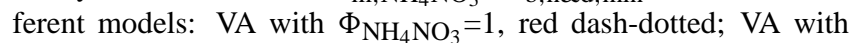
$\Phi_{\mathrm{NH}_{4} \mathrm{NO}_{3}}$ from Brechtel and Kreidenweis (2000), green dashed; VA with $a_{\mathrm{w}}$ from Clegg et al. (1998), black dotted; VA with $\Phi_{\mathrm{NH}_{4} \mathrm{NO}_{3}}$ from Brechtel and Kreidenweis (2000), green dashed; FP with $a_{\mathrm{W}}$ from Clegg et al. (1998) and $\rho$ from Tang (1996), black solid; FP with $a_{\mathrm{w}}$ and $\rho$ from Tang (1996), blue solid.

illustrated in Fig. 8, which shows the measured particle diameter plotted against relative humidity.

No distinct deliquescence or efflorescence transitions were observed, which is most probably due to a liquid-like state of the particles selected by DMA 1 . In single particle levitation experiments with pure $\mathrm{NH}_{4} \mathrm{NO}_{3}$ particles, Lightstone et al. (2000) observed a deliquescence transition at $R H=(61.8$ $\pm 0.3) \%$ at $298 \mathrm{~K}$, which is in a good agreement with theoretical predictions of $62 \%$ (Tang, 2000) and $61.5 \%$ (Clegg et al., 1998). On the other hand, they observed no efflorescence, which is consistent with earlier observations of liquidlike anhydrous $\mathrm{NH}_{4} \mathrm{NO}_{3}$ particles at $R H \approx 0 \%$ in single particle levitation experiments by Richardson and Hightower (1987). Thus we assume that the $\mathrm{NH}_{4} \mathrm{NO}_{3}$ particles selected by DMA 1 were not solid crystals but supersaturated liquid droplets, which underwent no deliquescence or efflorescence transitions.

Nevertheless, the mobility equivalent diameters observed upon dehydration in the $R H$ range of $40-80 \%$, i.e. below and above the theoretical deliquescence threshold, were up to $10 \%$ higher than the ones observed upon hydration. Due to the above considerations, the different mobility equivalent diameters cannot be attributed to a simple hysteresis between solid particles and liquid droplets or rearrangement of solid particle microstructure (shape and porosity) as described for $\mathrm{NaCl}$.

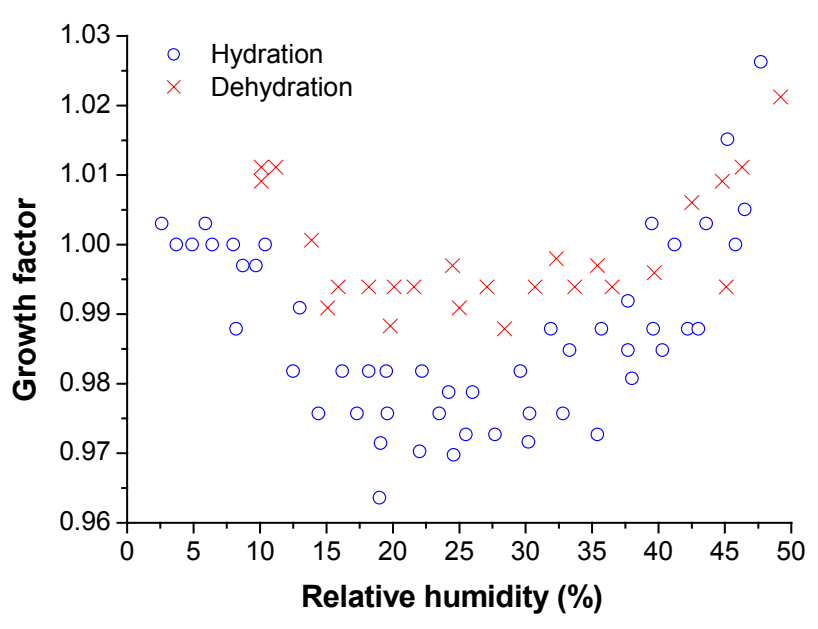

Fig. 9. Mobility equivalent growth factors of $\mathrm{NH}_{4} \mathrm{NO}_{3}$ particles with $D_{\mathrm{b}, \mathrm{i}}=99 \mathrm{~nm}$ observed upon hydration (H-TDMA mode 1) and dehydration (H-TDMA mode 2 ) at $R H<50 \%$.

Instead, the differences have to be explained by other processes which depend on particle pre- conditioning and lead to differences in particle mass (total content of $\mathrm{H}_{2} \mathrm{O}$ and $\mathrm{NH}_{4} \mathrm{NO}_{3}$ ) or chemical structure (crystalline or liquid-like modifications of the condensed phase), as will be discussed below.

\subsubsection{Chemical decomposition and evaporation}

Figure 9 displays the mobility equivalent growth factors, $g_{\mathrm{b}}=D_{\mathrm{b}} / D_{\mathrm{b}, \mathrm{i}}$, calculated from the diameter measurement data displayed in Fig. 8 for $R H<50 \%$, i.e. for the range of relative humidities where no hygroscopic growth but significant diameter reductions were observed. Upon hydration, $g_{b}$,hy was near unity up to $R H \approx 10 \%$, decreased by $\sim 3 \%$ in the $R H$ range of $10-20 \%$, and exhibited a minimum value of $g_{\mathrm{b}, \text { hy, } \min }=0.97$ at $R H=20-30 \%$. In the $R H$ range of 30$40 \%, g_{\text {b,hy }}$ re-increased to unity, and for $R H>40 \%$ it increased further as illustrated in Fig. 8. Upon dehydration $g_{\text {b,de }}$ was slightly below unity in the $R H$ range of $20-40 \%$ with $g_{\mathrm{b}, \mathrm{de}, \min }=0.99$.

Figure 10 illustrates the results obtained for pure $\mathrm{NH}_{4} \mathrm{NO}_{3}$ particles with $D_{\mathrm{b}, \mathrm{i}}=99 \mathrm{~nm}$ and $D_{\mathrm{b}, \mathrm{i}}=100 \mathrm{~nm}$ in H-TDMA mode 3 (hydration \& dehydration). In analogy to modes 1 and 2 the mobility equivalent growth factor in mode 3 was near unity up to $\mathrm{RH}_{2} \approx 10 \%$, but at higher relative humidity it exhibited a much more pronounced decrease by up to $10 \%$, reaching a minimum value of $g_{\mathrm{b}, \mathrm{h} \& \mathrm{~d}, \min }=0.90$ at $R \mathrm{H}_{2}=60$ $70 \%$, followed by a re-increase to unity at $\mathrm{RH}_{2} \approx 95 \%$.

Depending on temperature, pressure, humidity, and purity, ammonium nitrate can exist in several solid and liquidlike modifications with different chemical structures and densities (Clegg et al., 1998; Martin, 2000). Thus some of the effects described above could be due to transitions 
between different chemical structures of solid or liquid-like ammonium nitrate ("chemical restructuring"). On the other hand, $\mathrm{NH}_{4} \mathrm{NO}_{3}$ can also undergo chemical decomposition and evaporation in the form of $\mathrm{NH}_{3}$ and $\mathrm{HNO}_{3}$, leading to a loss of particle mass and reduction of dry solute mass equivalent diameter.

Lightstone et al. (2000) reported a significant loss of particle mass after a cycle of hydration and dehydration in their single particle levitation experiments with micrometersized $\mathrm{NH}_{4} \mathrm{NO}_{3}$ particles. They found that the volatilisation of $\mathrm{NH}_{4} \mathrm{NO}_{3}$ proceeded most efficiently in supersaturated droplets at $R H<40 \%$. Richardson and Hightower (1987) reported that the rate of decomposition and evaporation of $\mathrm{NH}_{4} \mathrm{NO}_{3}$ in liquid-like particles was about 20 times higher than for solid particles.

Our H-TDMA measurement results do not allow an unambiguous discrimination between the potential contributions of possible chemical restructuring or decomposition and evaporation to the mobility equivalent diameter decrease observed upon interaction of the investigated ammonium nitrate particles with water vapor. They demonstrate, however, that substantial effects and changes can occur on the multisecond time-scale of the H-TDMA experiments.

The fact that near-unity growth factors at very low and very high relative humidity with a pronounced minimum in between were observed in H-TDMA mode 3 (Fig. 10), which comprises a complete cycle of hydration and dehydration, clearly indicates that the restructuring or volatilisation was kinetically limited and most efficient at medium relative humidities. The most probable explanation for the results of H-TDMA mode 3 is chemical decomposition and evaporation of $\mathrm{NH}_{4} \mathrm{NO}_{3}$ with a maximum rate in supersaturated aqueous droplets (medium $R H$ ) and much lower rates in anhydrous $\mathrm{NH}_{4} \mathrm{NO}_{3}$ (low $R H$ ) and dilute aqueous solution droplets (high $R H$ ). This explanation is also consistent with the larger diameters observed in H-TDMA mode 2 relative to mode 1 at $40-80 \% R H$ (Fig. 8), since the particles in mode 2 are mostly kept at high $R H\left(R H_{2} \geq 85 \%\right)$ and experience medium $R H$ values only in DMA 2.

\subsubsection{Model calculations}

In Fig. 8 the measurement data obtained for $\mathrm{NH}_{4} \mathrm{NO}_{3}$ particles with $D_{\mathrm{b}, \mathrm{i}}=99 \mathrm{~nm}$ in H-TDMA modes 1 and 2 are compared to model calculations based on the dry solute mass equivalent diameter $D_{\mathrm{m}, \mathrm{NH}_{4} \mathrm{NO}_{3}}=D_{\mathrm{b}, \mathrm{h} \& \mathrm{~d}, \mathrm{~min}}=89 \mathrm{~nm}$ obtained in mode 3 (Fig. 10).

The FP model calculations based on $a_{\mathrm{w}}$ and $\rho$ from Tang (1996) and on $a_{\mathrm{w}}$ from Clegg et al. (1998) and $\rho$ from Tang (1996) agreed fairly well with each other (diameter deviations $<2 \%$ ) and with the measurement data observed upon dehydration (diameter deviations $<5 \%$ ), respectively. The agreement reflects the consistency of our H-TDMA results with the single particle levitation results of Tang (1996) and

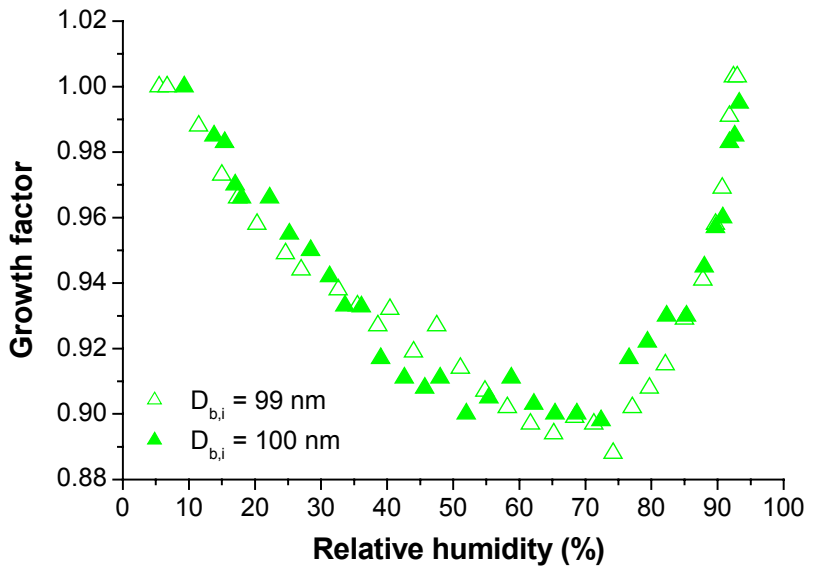

Fig. 10. Mobility equivalent growth factors of $\mathrm{NH}_{4} \mathrm{NO}_{3}$ particles with $D_{\mathrm{b}, \mathrm{i}}=99 \mathrm{~nm}$ and $D_{\mathrm{b}, \mathrm{i}}=100 \mathrm{~nm}$ observed upon hydration \& dehydration (H-TDMA mode $3, \mathrm{RH}_{2}$ ).

of Chan et al. (1992). The latter were used in the semiempirical ion-interaction model of Clegg et al. (1998).

The VA model calculations based on $\Phi_{\mathrm{NH}_{4} \mathrm{NO}_{3}}$ from Brechtel and Kreidenweis (2000) are in good agreement with the FP model results for $R H>85 \%$. At lower $R H$ the calculated diameters were just slightly lower than our hydration measurement data but up to $\sim 10 \%$ lower than our dehydration measurement data and the FP model results. These findings indicate that the H-TDMA experiments from which Brechtel and Kreidenweis (2000) derived the coefficients $\beta_{0, \mathrm{f}}$ and $Y_{\mathrm{f}}$ for their semi-empirical parameterisation of $\Phi_{\mathrm{NH}_{4} \mathrm{NO}_{3}}$ may have been affected by similar volatilisation or restructuring effects as our hydration measurements.

VA model calculations based on $a_{\mathrm{w}}$ from Clegg et al. (1998) confirm that the errors introduced by the assumption of volume additivity are small for dilute solutions and high relative humidities $(R H>85 \%)$. For highly supersaturated droplets at $R H \approx 30 \%$, however, the VA model diameters were $\sim 6 \%$ lower than the FP model which was based on the same water activity values but more realistic solution density values. On the other hand, VA model calculations based on the assumption of near-ideal solute properties with $\Phi_{\mathrm{NH}_{4} \mathrm{NO}_{3}}=1$ were up to $10 \%$ higher than the FP model calculations.

\subsection{Pure bovine serum albumin particles}

\subsubsection{Hygroscopic growth and microstructure}

The experimental results obtained for pure BSA particles with $D_{\mathrm{b}, \mathrm{i}}=98 \mathrm{~nm}$ in H-TDMA modes 1 and 2 are illustrated in Fig. 11. No significant differences between the diameters measured upon hydration and dehydration were observed, and the hygroscopic growth was much less pronounced than for inorganic salts. $D_{\mathrm{b}}$ was near constant at $R H<30 \%$ 


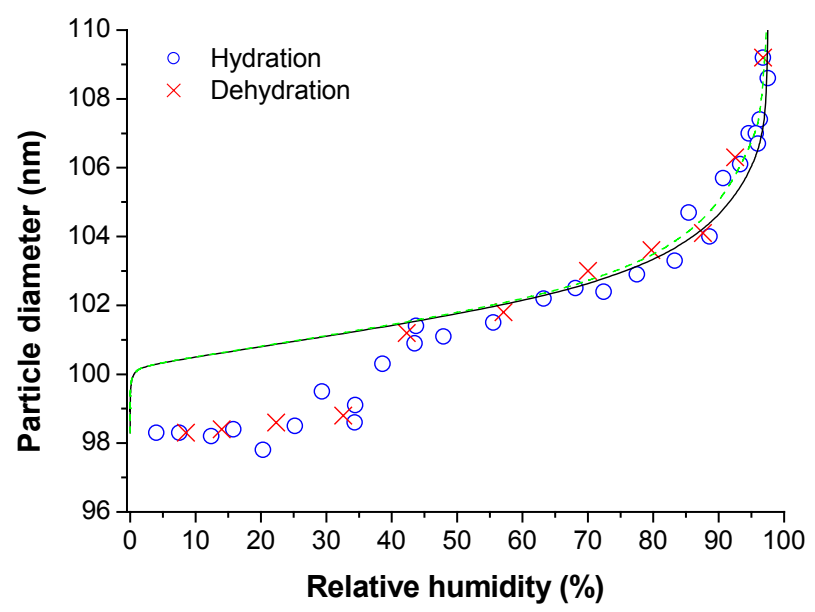

Fig. 11. Mobility equivalent diameters of pure BSA particles with $D_{\text {b,i }}=98$ nm observed upon hydration (H-TDMA mode 1) and dehydration (H-TDMA mode 2) compared to Köhler theory calculations with $D_{\mathrm{m}, \mathrm{BSA}}=D_{\mathrm{b}, \mathrm{i}}=98 \mathrm{~nm}$ and the VA model based on $\Phi_{\mathrm{BSA}}$ from osmotic pressure parameterisation: Kelvin term with $\sigma=\sigma_{\mathrm{W}}$, black solid; Kelvin term with $\sigma=0$, dashed green.

and exhibited a stepwise increase by $\sim 3 \%$ at $R H=30-45 \%$, which seems to indicate a sort of deliquescence transition, i.e. the transformation of the dry protein particle into a saturated aqueous solution or gel-like droplet. The further hygroscopic growth at $R H>45 \%$ was in good agreement with model calculations discussed below and led to a maximum increase of $D_{\mathrm{b}}$ by $\sim 10 \%$ at $R H=95 \%$. The mobility equivalent growth factors observed for BSA particles with $D_{\mathrm{b}, \mathrm{i}}=100 \mathrm{~nm}$ in H-TDMA mode 3 are displayed in Fig. 12 and exhibit no significant deviations from unity throughout the investigated $R H$ range. These results indicate that the BSA particles selected by DMA 1 were compact spheres as confirmed by electron microscopy (Fig. 6C1).

\subsubsection{Model calculations}

The Köhler theory calculations illustrated in Fig. 11 were performed with a VA model based on the osmotic pressure parameterisation of $v_{s} \Phi_{s}$, which has been derived from the osmotic pressure virial equation by Carnahan and Starling (1969) and is illustrated in Fig. 2b.

At $R H>45 \%$, i.e. above the apparent deliquescence transition, the deviations between modeled and measured diameters were less than $1 \%$. Proteins act as surfactants and reduce the surface tension of aqueous solutions, but we could not find a suitable parameterisation of $\sigma$ for concentrated solutions of BSA. To test the effect of surfactant activity, the Kelvin term in Eq. (9) has been neglected in one set of model calculations. This corresponds to the assumption of $\sigma \approx 0$ and led to a decrease of the calculated equilibrium $R H$ values by about $2 \%$, which seems to improve the agreement between modeled and measured diameters at high $R H$. The

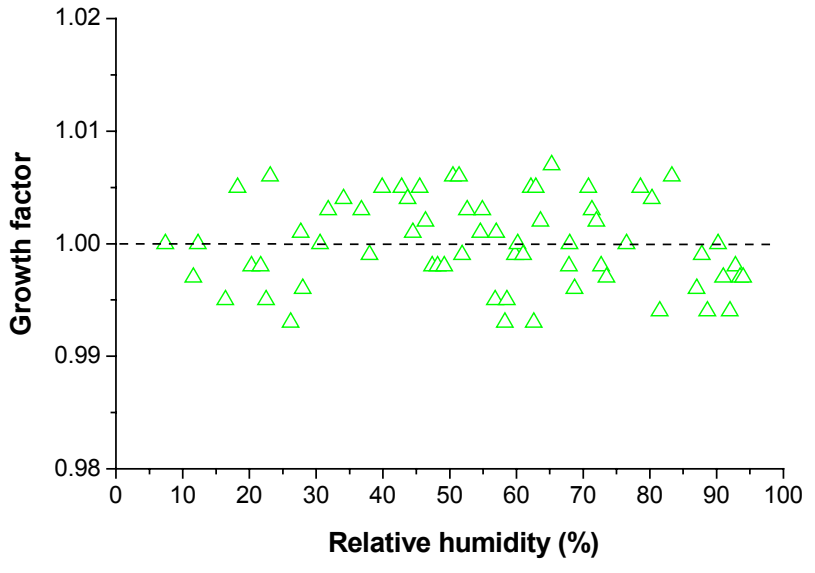

Fig. 12. Mobility equivalent growth factors of BSA particles with $D_{\mathrm{b}, \mathrm{i}}=100 \mathrm{~nm}$ observed upon hydration \& dehydration (H-TDMA mode $3, \mathrm{RH}_{2}$ ).

differences are, however, smaller than the measurement uncertainty.

\subsection{Mixed $\mathrm{NaCl}-\mathrm{BSA}$ and $\mathrm{NH}_{4} \mathrm{NO}_{3}$-BSA particles}

\subsubsection{Hygroscopic growth of NaCl-BSA particles}

The experimental results obtained for mixed NaCl-BSA particles with $D_{\mathrm{b}, \mathrm{i}}=99 \mathrm{~nm}$ in H-TDMA modes 1 and 2 are illustrated in Fig. 13.

Upon hydration of the particles with $10-75 \%$ BSA mass fraction in the dry solute mixture, $x_{s, \mathrm{BSA}}$, the measured mobility equivalent diameter exhibited a significant decrease as the relative humidity approached the deliquescence threshold, $R H_{\mathrm{d}}$. The most pronounced diameter reduction upon hydration was observed for the particles with $25 \%$ BSA $\left(g_{\mathrm{b}, \mathrm{hy}, \min }=0.86\right.$; Table 3$)$, indicating substantial microstructural rearrangements as will be discussed below. The deliquescence transitions were observed at similar relative humidities as for the pure $\mathrm{NaCl}$ particles, $R H_{\mathrm{d}}=(75 \pm 2) \%$; again the most pronounced deviation was observed for the particles with $25 \%$ BSA $\left(R H_{\mathrm{d}}=73 \%\right)$. The relative mobility equivalent diameter increase observed upon deliquescence exhibited a near-linear decrease with increasing BSA mass fraction $\left(\Delta_{\mathrm{r}, \mathrm{d}} D_{\mathrm{b}}\right.$, Table 3$)$. Upon hydration of the particles with $90 \%$ BSA no sharp deliquescence transition was observed. At 20-30\% and 60-70\% RH small stepwise increases of $D_{\mathrm{b}}$ by $3-5 \%$ were observed, followed by a steep increase at $R H>80 \%$. At $75-90 \% R H$ the diameters measured upon hydration were up to $\sim 5 \%$ lower than the ones measured upon dehydration, indicating a kinetic limitation of the hygroscopic growth of the deliquescent particles due to the high content of BSA which inhibits the uptake and release of water vapor as will be discussed below. 

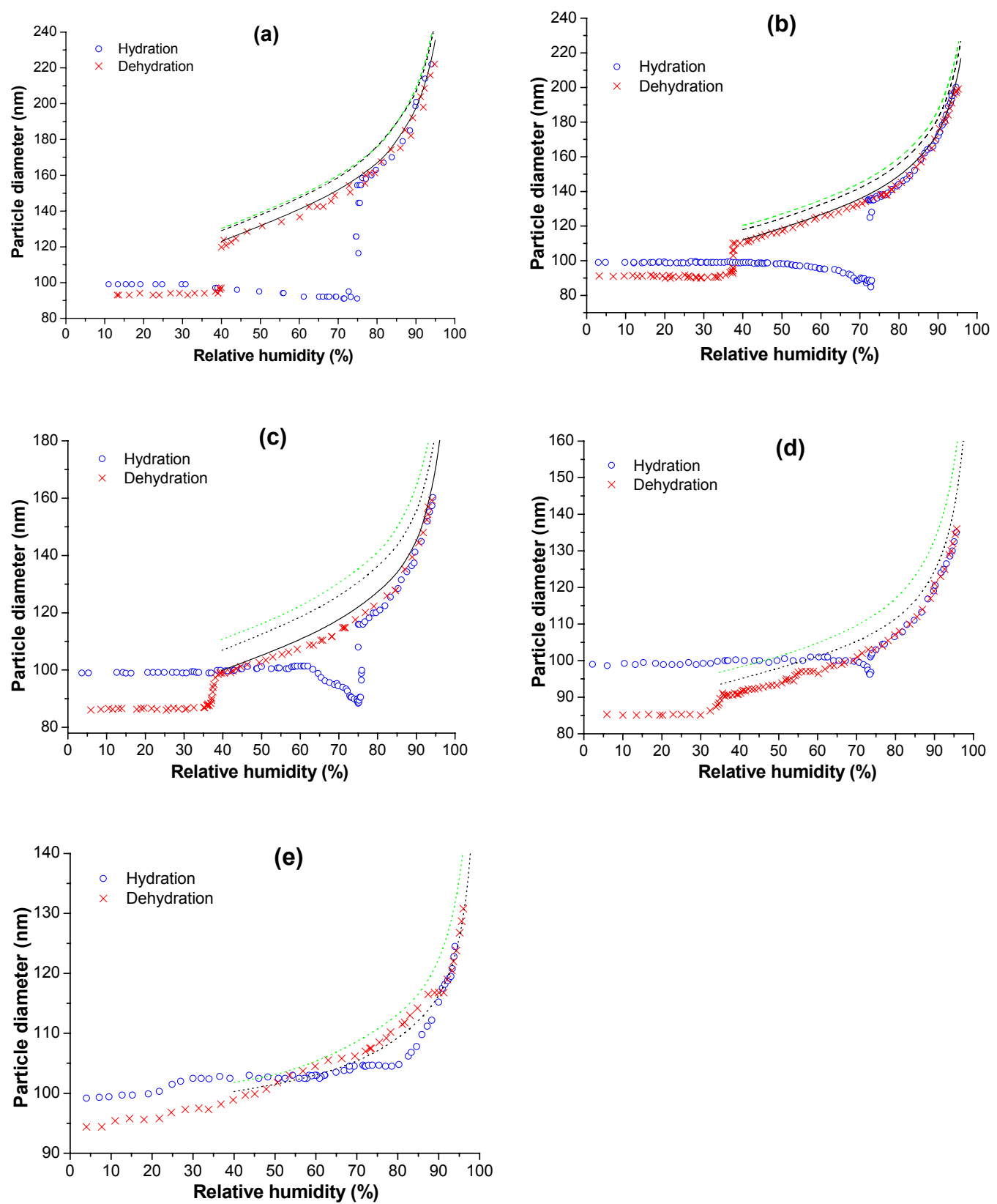

Fig. 13. Mobility equivalent diameters observed upon hydration (H-TDMA mode 1) and dehydration (H-TDMA mode 2) of mixed NaClBSA particles with $D_{\mathrm{b}, \mathrm{i}}=99 \mathrm{~nm}$ and BSA dry mass fractions of $10 \%$ (a), 25\% (b), $50 \%$ (c), $75 \%$ (d), and $90 \%$ (e) compared to Köhler theory calculations with different VA models ( $\Phi_{\mathrm{NaCl}}$ from Mokbel et al., 1997; $\Phi_{\mathrm{BSA}}$ from osmotic pressure parameterisation) and dry solute mass

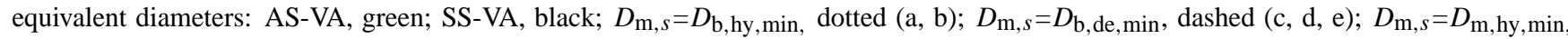

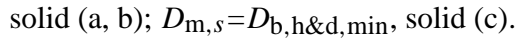

Upon dehydration of the particles with $10-75 \%$ BSA mass fraction, efflorescence transitions were observed at relative humidities which decreased with increasing $x_{s, \mathrm{BSA}}$, from $R H_{\mathrm{e}}=41 \%$ for $x_{s, \mathrm{BSA}}=0$ to $R H_{\mathrm{e}}=37 \%$ for $x_{s, \mathrm{BSA}}=75 \%(\mathrm{Ta}-$ ble 3). Apparently the protein inhibited the nucleation of salt crystals, leading to higher stability of the supersaturated salt solution. The relative mobility equivalent diameter change upon efflorescence also decreased with increasing BSA mass fraction, from $-29 \%$ for $x_{s, \mathrm{BSA}}=0$ to $-6 \%$ for $x_{s, \mathrm{BSA}}=75 \%$ $\left(\Delta_{\mathrm{r}, \mathrm{e}} D_{\mathrm{b}}\right.$, Table 3$)$. For particles with $90 \%$ BSA no pronounced efflorescence transition was observed. Instead, both the particles with $75 \%$ and with $90 \%$ BSA exhibited several small stepwise decreases of $D_{\mathrm{b}}$ in the $R H$ range of 35-70\% and $10-90 \%$, respectively (Fig. $13 \mathrm{~d}$ and e). The results of 
(a)

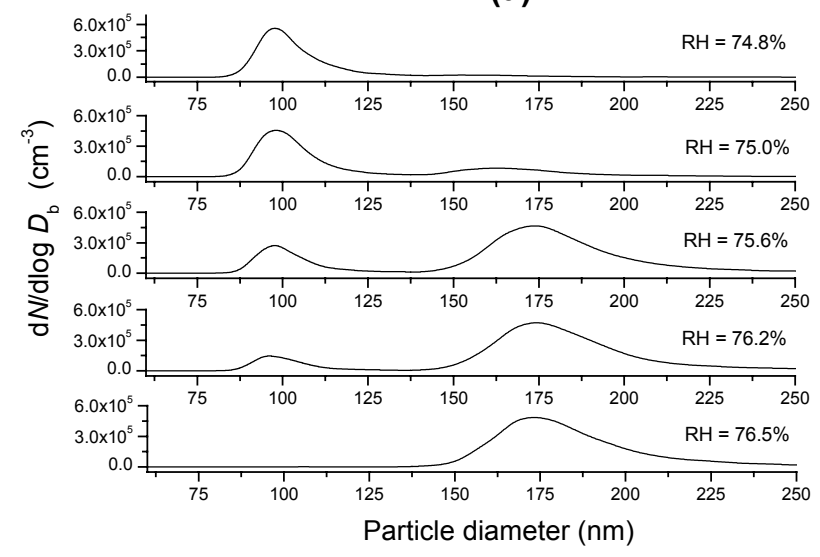

(b)

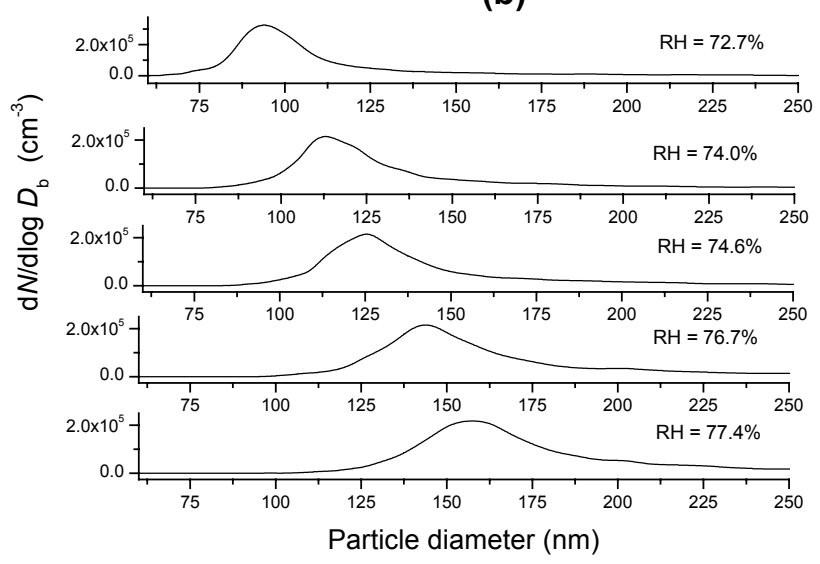

Fig. 14. Particle number size distributions measured at relative humidities close to the deliquescence threshold upon hydration of pure $\mathrm{NaCl}$ particles (a) and of mixed NaCl-BSA particles with $10 \%$ BSA dry mass fraction (b) with $D_{\mathrm{b}, \mathrm{i}}=99 \mathrm{~nm}$.

the hydration and dehydration experiments indicate a gel-like microstructure with embedded $\mathrm{NaCl}$ crystallites for the particles with high BSA content at medium $R H$, which is consistent with the TEM micrographs of deposited particles in Fig. 6 (B2 and B3) and will be discussed below.

Figure 14 shows the particle number size distributions measured at relative humidities close to the deliquescence threshold upon hydration of pure $\mathrm{NaCl}$ particles and mixed NaCl-BSA particles with $10 \%$ BSA mass fraction and $D_{\mathrm{b}, \mathrm{i}}=99 \mathrm{~nm}$.

For the pure $\mathrm{NaCl}$ particles bimodal size distributions with a sharp stepwise transition from dry particles with $D_{\text {b,hy,min }} \approx 98 \mathrm{~nm}$ to saturated aqueous solution droplets with $D_{\mathrm{b}, \mathrm{hy}} \approx 176 \mathrm{~nm}$ were observed. Only at $R H=75.0 \%$ a small particle mode was observed at an intermediate size of $D_{\text {b,hy }} \approx 160 \mathrm{~nm}$. The most plausible explanation for the observation of this intermediate mode is that it occurred exactly at the deliquescence threshold, and that most of the particles did not deliquesce immediately at the inlet of DMA 2 but only after having been exposed to the increased relative humidity inside DMA $2\left(\mathrm{RH}_{3}>\mathrm{RH}_{2}\right)$ for a period on the order of one to a few seconds. Thus the electrostatic sizing of the particles had already proceeded to a significant extent before their diameter increased to that of a saturated salt solution droplet. As a consequence, the mobility equivalent diameter determined by the overall process of electrostatic particle sizing in DMA 2 (duration $\sim 7.5 \mathrm{~s}$ ) was a superposition of the diameters of the dry particle and of the deliquesced droplet. For pure $\mathrm{NaCl}$ intermediate particle modes were observed only in very few measurements at $R H_{\mathrm{d}}$ and $R H_{\mathrm{e}}$, and the obtained mobility equivalent diameters were close to the diameters of the fully deliquesced or effloresced particles, respectively (Fig. 3). This implies that the deliquescence and efflorescence transitions of pure $\mathrm{NaCl}$ particles in H-TDMA modes 1 and 2 generally occurred right at the entrance into the drift zone of DMA 2 and proceeded near-instantaneously, i.e. on time scale of one second or less.

In contrast to the pure $\mathrm{NaCl}$ particles, the mixed particles with $10 \%$ BSA mass fraction exhibited only monomodal size distributions with a gradual increase from particles with $D_{\mathrm{b}} \approx 91 \mathrm{~nm}$ to deliquesced droplets with $D_{\mathrm{b}} \approx 155 \mathrm{~nm}$. The size distributions measured for particles with higher BSA content at $R H_{\mathrm{d}}$ and $R H_{\mathrm{e}}$ also exhibited intermediate modes in between the diameters of solid particles and deliquesced droplets, respectively (Fig. 13). These observations support that the deliquescence and efflorescence transitions of $\mathrm{NaCl}$ at $R H_{\mathrm{d}}$ and $R H_{\mathrm{e}}$, repectively, were kinetically limited by BSA and proceeded on a time scale of seconds. The fact that the inhibition occurred already at low mass and mole fractions of BSA ( $10 \%$ and $0.01 \%$, respectively) suggests that it is a surface effect. Most probably a BSA coating limits the access of water vapor to the particle core composed of $\mathrm{NaCl}$, which is consistent with the TEM micrographs of mixed NaCl-BSA particles shown in Figs. 6 (B1-B3) and discussed below.

\subsubsection{Microstructural rearrangement and electric charge ef- fects}

The minimum mobility equivalent growth factors observed upon hydration and dehydration of the mixed NaCl-BSA particles $\left(g_{\mathrm{b}, \mathrm{hy}, \min }, g_{\mathrm{b}, \mathrm{de}, \min }\right.$; Table 3$)$ correspond to mobility equivalent diameter and volume reductions of up to $16 \%$ and $40 \%$, respectively, which indicates highly irregular shape or high porosity of the initially selected particles and substantial microstructural rearrangement (compaction) upon interaction with water vapor.

Strong particle shrinking upon interaction with water vapor has been observed in earlier H-TDMA and microscopy 
Table 4. Minimum mobility equivalent growth factors of NaCl-BSA and $\mathrm{NH}_{4} \mathrm{NO}_{3}$-BSA particles observed in $\mathrm{H}-\mathrm{TDMA}$ operation modes 1-3 ( $\left.g_{\mathrm{b}, \mathrm{hy}, \min }, g_{\mathrm{b}, \mathrm{de}, \min }, g_{\mathrm{b}, \mathrm{h} \& \mathrm{~d}, \min }\right)$ for different initial diameters and neutralisation modes (measurement precision $\pm 1 \%$ ).

\begin{tabular}{cccccc}
\hline Salt & $\begin{array}{c}\text { BSA Dry Mass } \\
\text { Fraction }(\%)\end{array}$ & $\begin{array}{c}D_{\mathrm{b}, \mathrm{i}} \\
(\mathrm{nm})\end{array}$ & $g_{\mathrm{b}, \mathrm{hy}, \min }$ & $g_{\mathrm{b}, \mathrm{de}, \mathrm{min}}$ & $g_{\mathrm{b}, \mathrm{h} \& \mathrm{~d}, \mathrm{~min}}$ \\
\hline $\mathrm{NaCl}$ & 0 & 99 & 0.98 & 1.01 & 0.99 \\
& 50 & 201 & & & 0.96 \\
& $50^{*}$ & 99 & 0.89 & 0.88 & 0.83 \\
& 50 & 146 & 0.91 & 0.90 & \\
& 50 & 201 & 0.86 & 0.83 & 0.81 \\
\hline $\mathrm{NH}_{4} \mathrm{NO}_{3}$ & 0 & 99 & 0.97 & 0.99 & 0.90 \\
& 50 & 99 & 0.84 & & 0.80 \\
& $50 *$ & 99 & 0.92 & & 0.87 \\
\hline
\end{tabular}

* Neutralisation mode B

experiments with soot and $\mathrm{NaCl}$ high-temperature condensation aerosols, and it was attributed to the compaction of fractal agglomerate structures by capillary condensation effects (Weingartner et al., 1997; Mikhailov et al., 1997; Köllensperger et al., 1999; Krämer et al., 2000; Mikhailov et al., 2001). For fractal agglomerates, an enhancement of capillary restructuring is expected with increasing agglomerate size (Weingartner et al., 1997, Mikhailov et al., 1997).

Indeed $\mathrm{NaCl}-\mathrm{BSA}$ particles with $50 \%$ BSA mass fraction and initial diameters of 99-201 nm exhibited a significant decrease of minimum mobility equivalent growth factors with increasing particle size $\left(g_{\mathrm{b}, \mathrm{hy}, \mathrm{min}}, g_{\mathrm{b}, \mathrm{de}, \mathrm{min}}, g_{\mathrm{b}, \mathrm{h} \& \mathrm{~d}, \min }\right.$; Table 4). The TEM investigations showed that particles with $x_{\mathrm{s}, \mathrm{BSA}} \geq 50 \%$ have a near-spherical envelope shape with a dendritic or fractal-like core of $\mathrm{NaCl}$ (Figs. 6, B2 and B3). Such dendritic or fractal-like structures are characteristic for diffusion limited growth processes (Feder, 1988). Apparently the BSA matrix inhibits the diffusion of $\mathrm{NaCl}$ in the efflorescent droplets and the formation of compact $\mathrm{NaCl}$ crystals, which occurs upon efflorescence of droplets containing little or no BSA (Figs. A1, A2, B1).

Figure 15a illustrates the experimental results obtained for particles with $50 \%$ BSA and $D_{\mathrm{b}, \mathrm{i}}=99 \mathrm{~nm}$ in HTDMA mode 3 . Upon hydration \& dehydration without droplet formation $\left(\mathrm{RH}_{2}<\mathrm{RH}_{\mathrm{d}}\right)$ no significant size changes were observed up to $\mathrm{RH}_{2} \approx 30 \%$. In the relative humidity range $30 \%<R H_{2}<R H_{\mathrm{d}}$ the mobility equivalent growth factor exhibited a near-exponential decrease with $\mathrm{RH}_{2}$, reaching a

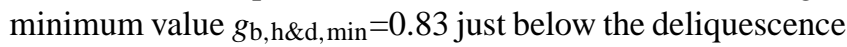
threshold. At $R H_{\mathrm{d}}$ the growth factor increased from 0.83 to 0.88 , i.e. a $6 \%$ increase of the dry particle mobility equivalent diameter occurred upon deliquescence in the conditioner tube and efflorescence in DMA 2. At $R H_{2}<R H_{\mathrm{d}}$ only small variations of $g_{\mathrm{b}, \mathrm{h} \& \mathrm{~d}, \mathrm{e}}$ were observed. Similar results were obtained for particles with $D_{\mathrm{b}, \mathrm{i}}=201 \mathrm{~nm}$ (Fig. 15b). In this case the near-exponential decrease of the mobility equivalent growth factor started only at higher relative humidity $\left(\mathrm{RH}_{2} \approx 50 \%\right.$ ), was steeper, reached a lower minimum value
( $\left.g_{\mathrm{b}, \mathrm{h} \& \mathrm{~d}, \min }=0.81\right)$, and exhibited a stronger increase at $R H_{\mathrm{d}}$ $(+10 \%)$.

The stepwise increase of mobility equivalent diameters and growth factors at $R H_{\mathrm{d}}$ in the hydration \& dehydration experiments (H-TDMA mode 3 ) with $\mathrm{NaCl}$-BSA particles (6-10\%; Fig. 15) is more pronounced but comparable to the analogous experiments with pure $\mathrm{NaCl}$ particles $(3-5 \%$; Fig. 5). Thus we suppose that this increase reflects a transformation of $\mathrm{NaCl}$ crystallites inside the mixed $\mathrm{NaCl}-\mathrm{BSA}$ particles from irregular to near-cubic shape. The variations of $g_{\mathrm{b}, \mathrm{h} \& \mathrm{~d}}$ at $\mathrm{RH}_{2}>\mathrm{R} \mathrm{H}_{\mathrm{d}}$ are probably due to additional microstructural rearrangements of the $\mathrm{NaCl}$ crystallites and the BSA matrix. The differences observed between the particles with $D_{\mathrm{b}, \mathrm{i}}=99 \mathrm{~nm}$ and $D_{\mathrm{b}, \mathrm{i}}=201 \mathrm{~nm}$ are fully consistent with the kinetic limitation of the shape transformation of $\mathrm{NaCl}$ crystallites and with the fractal-like structure of the $\mathrm{NaCl}$ core of the particles discussed above.

Figure 13c shows that the mobility equivalent diameters of effloresced $\mathrm{NaCl}-\mathrm{BSA}$ particles with $50 \%$ BSA mass fraction and $D_{\mathrm{b}, \mathrm{i}}=99 \mathrm{~nm}$ were essentially the same in H-TDMA modes 2 and $3\left(D_{\mathrm{b}, \mathrm{de}, \mathrm{e}} \approx D_{\mathrm{b}, \mathrm{h} \& \mathrm{~d}, \mathrm{e}}=87 \mathrm{~nm}\right)$. Apparently the $\mathrm{NaCl}$ crystallites in effloresced $\mathrm{NaCl}-\mathrm{BSA}$ particles retained their near-cubic shape also in mode 2 , which indicates that BSA inhibits the transformation of the crystallites from nearcubic to near-spherical shape. The higher stability of the near-cubic shape of small $\mathrm{NaCl}$ crystallites in mixed $\mathrm{NaCl}$ BSA particles was confirmed by TEM micrographs. Figure 6 (B1) shows that $100 \mathrm{~nm}$ and smaller $\mathrm{NaCl}$ crystallites in particles generated from a NaCl-BSA solution with $25 \%$ BSA mass fraction exhibit sharper corners than those generated from a pure $\mathrm{NaCl}$ solution in Fig. 6 (A1).

The crystallites from the mixture appear to be covered by a BSA layer, which inhibits the transformation to nearspherical shape by interaction with water vapor (diffusion barrier). This is in agreement with the observation that BSA kinetically limits the deliquescence and efflorescence of $\mathrm{NaCl}$ in mixed particles as outlined above. 

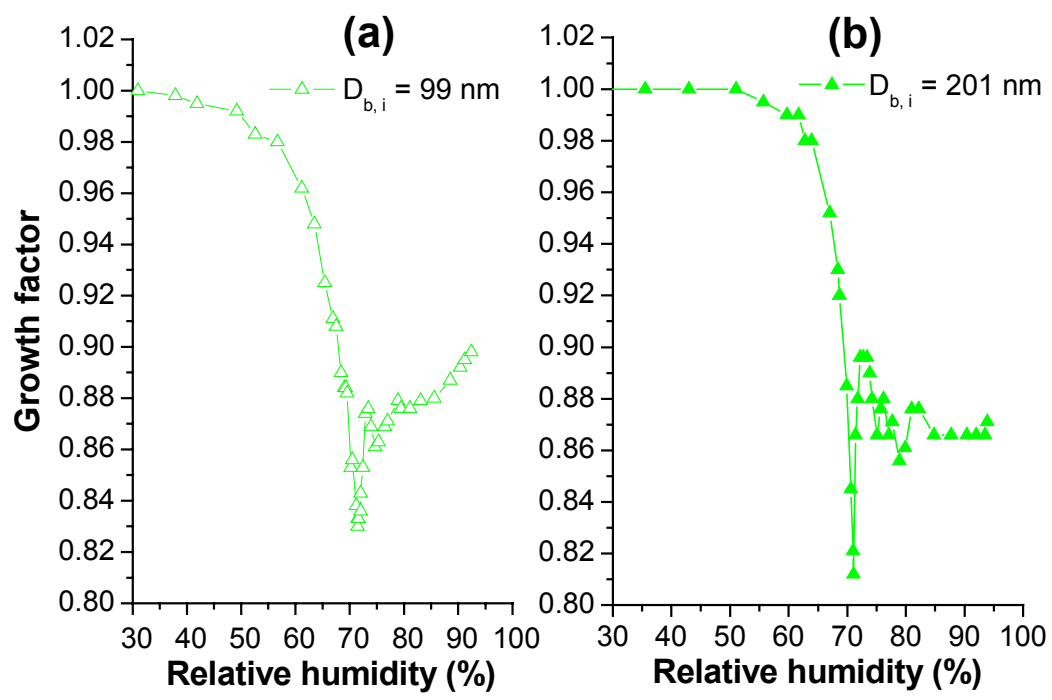

Fig. 15. Mobility equivalent growth factors of NaCl-BSA particles with $50 \%$ BSA dry mas fraction, $D_{\mathrm{b}, \mathrm{i}}=99 \mathrm{~nm}(\mathbf{a})$ and $D_{\mathrm{b}, \mathrm{i}}=201 \mathrm{~nm}(\mathbf{b})$ observed upon hydration \& dehydration (H-TDMA mode $3, \mathrm{RH}_{2}$ ).

Obviously the transformation of $\mathrm{NaCl}$ crystallites from near-cubic to near-spherical shape (v.v.) and its kinetic limitation influence the microstructural rearrangements observed for mixed NaCl-BSA particles. These effects alone, however, are not sufficient to explain the differences between the mobility diameters of the initially selected particles and the effloresced particles, especially the large deviations observed for $25-75 \%$ BSA mass fraction $\left(g_{\mathrm{b}, \mathrm{hy}, \min }, g_{\mathrm{b}, \mathrm{de}, \min }\right.$, $g_{\mathrm{b}, \mathrm{h} \& \mathrm{~d}, \min }$; Tables 3 and 4).

The most probable reason for the very different properties of the mixed $\mathrm{NaCl}-\mathrm{BSA}$ particles upon size selection by DMA 1 after nebulisation and drying (efflorescence in SDD or DMA 1) and the particles analyzed by DMA 2 after conditioning (hydration and/or dehydration with or without deliquescence and efflorescence in the conditioner tube or DMA 2) are electric charge effects.

BSA and other albumins are characterised by a high content of amino acid residues with ionogenic functional groups (arginine, lysine, aspartic and glutamic acid, etc.; Brown, 1975; NCBI protein database, http://www.ncbi.nlm.nih.gov), and thus they carry a high number of elementary charges in aqueous solution. The actual number of positive and negative elementary charges and the resulting net charge of the molecule depend primarily on the $\mathrm{pH}$ and ionic strength of the solution. The isoelectric point, i.e. the $\mathrm{pH}$ value at which a protein has zero net charge, is $4.5-5.0$ for BSA. Under neutral conditions $(\mathrm{pH} \approx 7)$, BSA molecules carry a negative net electric charge of about 10 elementary charges (Peters, 1985), depending on the abundance of salt ions in the solution.

Molecular interactions of globular proteins are usually described in terms of Derjaguin, Landau, Verwey, and Over- beek (DLVO) theory (Derjaguin, et al., 1987; Verwey, and Overbeek, 1948), which is based on the balancing of van der Waals attraction and electrostatic repulsion (coulomb forces). According to basic DLVO theory, electrostatic repulsion between protein molecules should decrease upon addition of salts because of charge neutralisation by counterions, which has been confirmed in experiments with low salt concentrations and ion strengths. In solutions with high salt concentrations and ion strengths, however, repulsion was found to be enhanced (Paunov et al., 1996). This so-called non-DLVO behavior is characteristic for globular protein solutions, and can be attributed to hydration effects, i.e. to the repulsive interaction of hydration shells formed around salt ions adsorbed on the protein surface (Petsev et al., 2000). Moreover, repulsion can be enhanced by excess electric charges, i.e. when solution droplets and particles carry net charges due to uncompensated anions or cations. Mainelis et al. (2001) reported that aerosol particles composed of biological materials and generated by nebulisation of aqueous solutions or suspensions retained excess electric charges of the nebulised droplets upon drying. They found that bacterial cells and spores (Pseudomanas fluorescens, Bacillus subtilis var. niger) with a mean diameter $0.7 \mu \mathrm{m}$ carried net electric charges of up to $10^{4}$ elementary charges or more, depending on the dispersion method. Moreover, Gu and $\mathrm{Li}$ (1998) have shown that the net charging of droplets generated by nebulisation of aqueous solutions is generally increased with increasing ionic strength. Thus the nebulised NaCl-BSA solution droplets may have carried high net electric charges, leading to enhanced electrostatic repulsion (Coulomb forces between the excess charges) and to a reduced packing density of protein molecules in the dried particles. 
To test the influence of electric charge effects, some experiments have been performed in aerosol neutralisation mode B (Fig. 1), in which the aerosol flow from the nebuliser was passed through a neutraliser $\left(10 \mathrm{mCi}{ }^{85} \mathrm{Kr}\right)$ before particle drying in the SDD. For the particles with 50\% BSA mass fraction and $D_{\mathrm{b}, \mathrm{i}}=99 \mathrm{~nm}$, the particle diameter decrease due to microstructural rearrangement upon hydration and dehydration in neutralisation mode B was significantly less pronounced than in neutralisation mode $A$, where a neutraliser was applied only after particle drying in the SDD

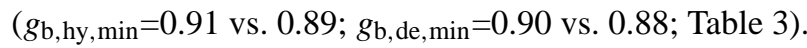

A similar but more pronounced effect of neutralisation mode B was observed for mixed $\mathrm{NH}_{4} \mathrm{NO}_{3} \mathrm{BSA}$ particles with $50 \%$ BSA dry mass fraction and $D_{\mathrm{b}, \mathrm{i}}=99 \mathrm{~nm}$. As illustrated in Fig. 16, the decrease of mobility equivalent diameters with increasing $R H$ observed in H-TDMA operation modes 1 and 3 was strongly reduced in neutralisation mode $B$ relative to

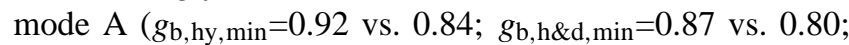
Table 4).

In contrast, the results of test experiments performed with pure $\mathrm{NH}_{4} \mathrm{NO}_{3}$ particles and $D_{\mathrm{b}, \mathrm{i}}=99 \mathrm{~nm}$ in neutralisation mode $\mathrm{B}$ (H-TDMA modes 1 and 3 ) were practically identical to the results obtained in neutralisation mode $\mathrm{A}$ which are displayed in Figs. 9, 10, and 11. These test experiments and the results obtained with pure BSA particles, which exhibited no restructuring upon interaction with water vapor (Fig. 12), confirm that the influence of charge effects was specific for protein-salt mixtures and did not significantly affect the experiments with pure solutes. The influence of mixed solute composition on the effect of excess charge neutralisation in mode $\mathrm{B}$ (stronger effect for $\mathrm{NH}_{4} \mathrm{NO}_{3}$-BSA than for $\mathrm{NaCl}$ BSA) may be due to different ion-interactions or to different size distributions of the droplets generated by nebulisation and passed through the neutraliser.

Based on the experimental results and considerations outlined above, we propose the following hypotheses to explain the apparent microstructural differences between the particles selected by DMA 1 after nebulisation and drying (efflorescence in SDD or DMA 1) and the particles analyzed by DMA 2 after conditioning (hydration and/or dehydration with or without deliquescence and efflorescence in the conditioner tube or DMA 2):

1. The aqueous NaCl-BSA solution droplets generated by nebulisation carried excess electric charges which enhanced electrostatic repulsion between the protein molecules and led to the formation of porous agglomerates upon efflorescence of the solution droplets in the SDD or DMA 1.

2. The electric charging of aqueous solution droplets generated by nebulisation was strongly enhanced by the interaction of salt ions and proteins (adsorption), because no significant charge effects had been observed for pure $\mathrm{NaCl}$ and pure BSA particles.

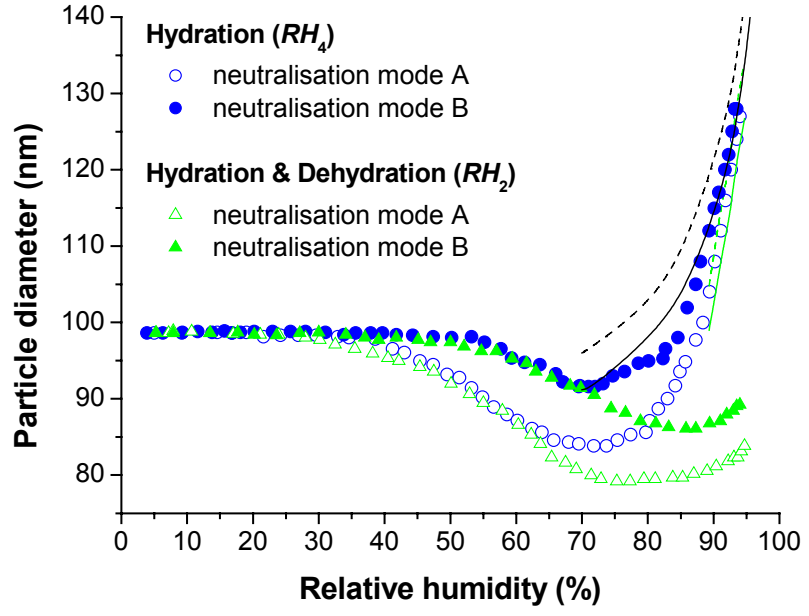

Fig. 16. Mobility equivalent diameters observed in H-TDMA modes 1 and 3 and neutralisation modes $\mathrm{A}$ and $\mathrm{B}$ for mixed $\mathrm{NH}_{4} \mathrm{NO}_{3}$-BSA particles with $D_{\mathrm{b}, \mathrm{i}}=99 \mathrm{~nm}$ and $50 \%$ BSA dry mass fraction compared to Köhler theory calculations using the SS-VA model with different parameterisations and dry solute mass equivalent diameters: $a_{\mathrm{W}}$ from Clegg et al. (1998), black; $\Phi_{\mathrm{NH}_{4} \mathrm{NO}_{3}}$ from Brechtel and Kreidenweis (2000), green; $D_{\mathrm{m}, s}=D_{\mathrm{b}, \mathrm{hy} \text {, min }}$, dashed; $D_{\mathrm{m}, s}=D_{\mathrm{b}, \mathrm{h} \& \mathrm{~d}, \mathrm{~min}}$, solid.

3. The dried particles retained their porous agglomerate structure upon neutralisation and size selection by DMA 1.

4. Upon interaction with water vapor the agglomerate structure of the single-charged particles selected by DMA 1 was efficiently compacted by capillary condensation $\left(R H<R H_{\mathrm{d}}\right)$ or deliquescence and efflorescence $\left(R H<R H_{\mathrm{d}}\right)$, involving the transformation of $\mathrm{NaCl}$ crystallites between near-cubic and near-spherical shape.

5. The porosity or void fraction of the agglomerates and the corresponding extent of restructuring upon interaction with water vapor were determined by the chemical composition and electric charge of the nebulised solution droplets, as will be detailed below (Table 5).

\subsubsection{Model calculations for NaCl-BSA particles}

Köhler theory calculations for the hygroscopic growth of mixed NaCl-BSA particles have been performed using the AS- and SS-VA models outlined in Sects. 3.1.2.3 and 3.1.2.4 with $\Phi_{\mathrm{NaCl}}$ and $\Phi_{\mathrm{BSA}}$ from Eqs. (7), (24), (19), and (26), respectively. In Fig. 13 the model results obtained with different values of $x_{s, \mathrm{BSA}}$ and $D_{\mathrm{m}, s}$ are compared to the $\mathrm{H}$ TDMA measurement data.

For the particles with 10 and $25 \%$ BSA mass fraction in the dry solute mixture (Figs. 14a and b), the AS- and SSVA models agreed to within $\leq 2 \%(\mathrm{AS}>\mathrm{SS})$. The diameters 
Table 5. Dynamic shape factor $(\chi)$ and envelope void fraction $(f)$ of NaCl-BSA particles with initial diameter $D_{\mathrm{b}, \mathrm{i}}=99 \mathrm{~nm}$ based on dry mass equivalent diameters $\left(D_{\mathrm{m}, s}\right.$, mean \pm standard deviation of 8 data points $)$ derived from SS-VA model calculations.

\begin{tabular}{ccccccc}
\hline & \multicolumn{3}{c}{ Initial Particles } & \multicolumn{3}{c}{ Restructured Particles } \\
BSA Dry Mass Fraction & $D_{\mathrm{m}, s}$ & $\chi_{\mathrm{i}}$ & $f_{\mathrm{i}}$ & $D_{\mathrm{b}, \min }$ & $\chi_{\min }$ & $f_{\min }$ \\
$(\%)$ & & & $(\%)$ & $(\mathrm{nm})$ & & $(\%)$ \\
\hline 10 & $85.8 \pm 0.4$ & 1.28 & 25 & $91^{\mathrm{a}}$ & 1.11 & 5 \\
25 & $82.7 \pm 0.6$ & 1.37 & 33 & $87^{\mathrm{a}}$ & 1.10 & 3 \\
50 & $79.2 \pm 0.4$ & 1.49 & 49 & $87^{\mathrm{b}}$ & 1.19 & 25 \\
50 & $79.2 \pm 0.4$ & 1.49 & 49 & $82^{\mathrm{c}}$ & 1.05 & 8 \\
75 & $84.0 \pm 0.4$ & 1.33 & 39 & $85^{\mathrm{b}}$ & 1.02 & 4 \\
90 & $95.4 \pm 0.8$ & 1.07 & 11 & $94^{\mathrm{b}}$ & 0.97 & -5 \\
\hline
\end{tabular}

${ }^{\mathrm{a}} D_{\mathrm{b}, \mathrm{hy}, \min } ;{ }^{\mathrm{b}} D_{\mathrm{b}, \mathrm{de}, \min } ;{ }^{\mathrm{c}} D_{\mathrm{b}, \mathrm{h} \& \mathrm{~d}, \min }$

calculated with the minimum diameter observed upon hydration $D_{\mathrm{m}, s}=D_{\mathrm{b}, \text { hy, } \min }$ were $\sim 5 \%$ higher than the measurement data $\left(\sim 15 \%\right.$ with $\left.D_{\mathrm{m}, s}=D_{\mathrm{b}, \mathrm{i}}\right)$. Since the TEM investigations indicated near-cubic shape for the mixed $\mathrm{NaCl}-\mathrm{BSA}$ particles, we calculated an envelope shape corrected diameter $D_{\mathrm{m}}$,hy,min by inserting $D_{\mathrm{b}, \text { hy,min }}$ and the dynamic shape factor for cubic particles $\chi_{\text {cube }}=1.08$ in Eq. (29). The model results obtained with the SS-VA model and $D_{\mathrm{m}, s}=D_{\mathrm{m} \text {,hy,min }}$ were in good agreement with the measurement data.

At $x_{s, \mathrm{BSA}}=50 \%$ the results of the AS-VA model were $\sim 5 \%$ higher than those of the SS-VA model (Fig. 13c). The diameters calculated with the minimum diameter observed upon dehydration $D_{\mathrm{m}, s}=D_{\mathrm{b} \text {,de, min }}$ were $\sim 10 \%$ higher than the measurement data $\left(\sim 25 \%\right.$ with $\left.D_{\mathrm{m}, s}=D_{\mathrm{b}, \mathrm{i}}\right)$. The results obtained with the SS-VA model and the minimum diameter observed in operation mode $3\left(D_{\mathrm{m}, s}=D_{\mathrm{b}, \mathrm{h} \& \mathrm{~d} \text {,min }}\right)$ were in fair agreement with the measurement data (differences $\leq 5 \%$ ).

For the particles with higher BSA mass fractions (Fig. 14d and e), similar agreement was achieved with the SS-VA model and the minimum diameter observed upon dehydration $D_{\mathrm{m}, s}=D_{\mathrm{b}, \mathrm{de}, \min }$. For $x_{s, \mathrm{BSA}}=90 \%$ and $R H>90 \%$ the model results practically coincide with the measurement data. At $70-90 \% R H$, however, the diameters measured upon hydration were significantly lower than the calculated diameters whereas the diameters measured upon dehydration were significantly higher. These findings confirm that the protein at high concentration inhibits the uptake and release of water vapor and leads to a kinetic limitation of hydration and dehydration on the time-scale of the H-TDMA experiments.

In any case, the correct determination of $D_{\mathrm{m}, s}$ turned out to be critical for Köhler theory calculations of the hygroscopic growth of particles with complex composition and microstructure. Moreover, the SS-VA approach appears to be fairly well suited for the modeling of particles containing organic macromolecules, whereas the AS-VA approach usually applied for inorganic salt mixtures turned out to be less suitable.
Thus the SS-VA model was used to calculate dynamic shape factors and void fractions for the characterisation of different microstructural states of the non-deliquesced $\mathrm{NaCl}$ BSA particles: after size selection in DMA $1\left(D_{\mathrm{b}, \mathrm{i}}\right)$ and at the minimum diameters observed in the different H-TDMA modes of operation, i.e. after exposure to water vapor without deliquescence in modes $1\left(D_{\mathrm{b}, \mathrm{hy}, \min }\right)$ or $3\left(D_{\mathrm{b}, \mathrm{h} \& \mathrm{~d}, \min }\right)$, or after efflorescence in mode $2\left(D_{\mathrm{b}, \mathrm{de}, \mathrm{min}}\right)$.

To minimise statistical errors, the droplet diameters measured in the relative humidity range of $75-94 \%$ (89-94\% for $x_{s, \mathrm{BSA}}=0.9$ ) were least-squares fitted with a third-order polynome. From the given interval and polynomial fit eight data pairs of relative humidity and droplet diameter $(R H$, $D_{\mathrm{b}}=D_{\mathrm{m}}$ ) were taken to calculate the corresponding values of $g_{\mathrm{m}, s}$ through iterative solving of Eq. (9) with $\Phi_{\mathrm{NaCl}}$ and $\Phi_{\text {BSA }}$ given by Eqs. (24), (7), (26), and (19), respectively.

The pairs of $D_{\mathrm{m}}$ and $g_{\mathrm{m}, \mathrm{s}}$ obtained from this procedure were inserted in Eq. (2), and the arithmetic mean and standard deviation of the resulting $D_{\mathrm{m}, s}$ values are listed in Table 5. $D_{\mathrm{m}, s}$ and the mobility equivalent diameter corresponding to the investigated microstructural state of the non-deliquesced particle $\left(D_{\mathrm{b}, \mathrm{i}}, D_{\mathrm{b}, \mathrm{hy}, \min }, D_{\mathrm{b}, \mathrm{h} \& \mathrm{~d}, \min }\right.$, or $D_{\text {b,de,min }}$ ) were inserted in Eqs. (29) and (30) to obtain the corresponding dynamic shape factor $\chi$. Finally $\chi$ and an appropriate envelope shape factor $\kappa$ (1.08 for the near-cubic particles at $x_{s, \mathrm{BSA}} \leq 25 \% ; 1.00$ for the near-spherical particles at $x_{s, \mathrm{BSA}} \geq 25 \%$ ) were inserted in Eqs. (31) and (32) to calculate the envelope void fraction $f$.

The maximum void fraction calculated for the initial particles size selected by DMA 1 was almost $50 \%$ for the particles with $x_{s, \mathrm{BSA}}=0.5$. The initial void fraction decreased towards lower and higher BSA mass fractions, which confirms that the formation of porous agglomerate structures was due to specific ion-protein interactions.

For the particles restructured by interaction with water vapor or deliquescence and efflorescence the calculated void fraction was mostly less than $5 \%$, which is at the edge of measurement and modeling precision, as outlined above and confirmed by the negative value of $5 \%$ for effloresced 
particles with $x_{s, \mathrm{BSA}}=0.9$ in H-TDMA mode 2 . Only for the particles with $x_{s, \mathrm{BSA}}=0.5$ significant void fractions were calculated after restructuring: $25 \%$ after deliquescence and efflorescence in H-TDMA mode 2 and $8 \%$ after interaction with water vapor without deliquescence and efflorescence in H-TDMA mode 3. This is consistent with the mechanisms and kinetic limitations of the restructuring process discussed above.

4.4.4 Hygroscopic growth, restructuring, volatilisation, and model calculations for $\mathrm{NH}_{4} \mathrm{NO}_{3}$-BSA particles

The experimental results obtained for $\mathrm{NH}_{4} \mathrm{NO}_{3}$-BSA particles with $D_{\mathrm{b}, \mathrm{i}}=99 \mathrm{~nm}$ and $x_{s, \mathrm{BSA}}=50 \%$ in H-TDMA modes 1 and 3 are illustrated in Fig. 16. As for pure $\mathrm{NH}_{4} \mathrm{NO}_{3}$ particles no pronounced deliquescence transition was observed upon hydration (H-TDMA mode 1). In neutralisation mode A the measured mobility equivalent diameters were near constant up to $R H \approx 30 \%$, followed by a pronounced decrease to a minimum at $R H \approx 70-75 \%\left(g_{\mathrm{b}, \mathrm{hy}, \min , \mathrm{A}}=0.84\right)$, and a subsequent steep increase. In neutralisation mode B similar effects were observed, but the diameter reduction started only at $R H \approx 30 \%$ and was less pronounced $\left(g_{\mathrm{b}, \mathrm{hy}, \mathrm{min}, \mathrm{B}}=0.92\right)$. In H-TDMA mode 3 the measured diameters were almost the same as in H-TDMA mode 1 up to $R H \approx 65 \%$. In neutralisation mode A minimum diameters were observed at

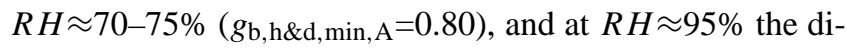
ameter reincreased to the same value which was observed as a minimum in H-TDMA mode 1. Again neutralisation mode B showed similar effects but a less pronounced minimum at higher relative humidity ( $\left.g_{\mathrm{b}, \mathrm{h} \& \mathrm{~d}, \min , \mathrm{B}}=0.87, \mathrm{RH} \approx 85 \%\right)$.

In view of the results described and discussed above for mixed $\mathrm{NaCl}-\mathrm{BSA}$ and $\mathrm{NH}_{4} \mathrm{NO}_{3}$ particles, the most plausible explanation for the $\mathrm{NH}_{4} \mathrm{NO}_{3}$-BSA results is:

1. Porous agglomerates are formed upon particle generation by nebulisation and drying due to ion-protein interactions and electric charge effects.

2. The diameter reductions upon interaction with water vapor is due to a combination of restructring (compaction) of the porous agglomerates and volatilisation of $\mathrm{NH}_{4} \mathrm{NO}_{3}$ : The 7-8\% difference between the minimum diameters observed in neutralisation modes $\mathrm{A}$ and B $\left(g_{\mathrm{b}, \mathrm{hy}, \min , \mathrm{A}}-g_{\mathrm{b}, \mathrm{hy}, \min , \mathrm{B}} ; g_{\mathrm{b}, \mathrm{h} \& \mathrm{~d}, \min , \mathrm{A}}-g_{\mathrm{b}, \mathrm{h} \& \mathrm{~d}, \min , \mathrm{B}}\right)$ can be attributed to different porosities of the initially selected particles due to different electric charge effects. The 5-6\% difference between the minimum diameters observed in H-TDMA modes 1 and 3 ( $g_{\mathrm{b}, \mathrm{hy}, \mathrm{min}, \mathrm{A}-}$ $\left.g_{\mathrm{b}, \mathrm{h} \& \mathrm{~d}, \min , \mathrm{A}} ; g_{\mathrm{b}, \mathrm{hy}, \min , \mathrm{B}}-g_{\mathrm{b}, \mathrm{h} \& \mathrm{~d}, \min , \mathrm{B}}\right)$ appears to be largely due to volatilisation of $\mathrm{NH}_{4} \mathrm{NO}_{3}$, because the minimum diameter observed in mode 1 is essentially the same as the diameters observed in mode 3 at $R H \approx 95 \%$ where volatilisation was found to be negligible for pure $\mathrm{NH}_{4} \mathrm{NO}_{3}$.
3. BSA apparently inhibits the volatilisation of $\mathrm{NH}_{4} \mathrm{NO}_{3}$, because no significant diameter reductions were observed at $R H<30 \%$ for mixed $\mathrm{NH}_{4} \mathrm{NO}_{3}$-BSA particles in contrast to pure $\mathrm{NH}_{4} \mathrm{NO}_{3}$ particles. Most probably the salt is embedded in a protein matrix, which limits the access of water vapor as found for the mixed $\mathrm{NaCl}-\mathrm{BSA}$ particles. Moreover, the protein may influence both the chemical decomposition of the salt and the evaporation of the decomposition products (Cruz et al., 2000). In any case it can affect the atmospheric abundance and measurement of particulate ammonium nitrate (Bergin et al., 1997; Ten Brink et al., 1997; Moya et al., 2002).

The Köhler theory calculations illustrated by green lines in Fig. 16 have been performed using the SS-VA model with $\Phi_{\text {BSA }}$ from Eqs. (19) and (26) and with $\Phi_{\mathrm{NH}_{4} \mathrm{NO}_{3}}$ from Eq. (6) and Clegg et al. (1998), respectively. The diameters calculated with $D_{\mathrm{m}, s}=D_{\mathrm{b}, \mathrm{h} \& \mathrm{~d}, \mathrm{~min}, \mathrm{~A}}$ were in fair agreement with the measurement values from neutralisation mode $\mathrm{A}$ at $R H \geq 90 \%$ (deviations $\leq 5 \%$ ). At lower $R H$ and for $D_{\mathrm{m}, s}=D_{\mathrm{b}, \mathrm{hy}, \min , \mathrm{A}}$ the calculated diameters were $5-15 \%$ higher than the measurement data. The humidity dependence of the deviations between model and measurement data seems to reflect the humidity dependence of chemical decompostion. With $\Phi_{\mathrm{NH}_{4} \mathrm{NO}_{3}}$ from Eq. (13) the diame-

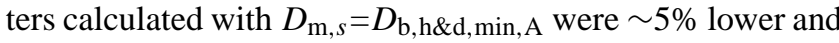
with $D_{\mathrm{m}, s}=D_{\mathrm{b}, \text { hy,min, A }}$ they were $\sim 3 \%$ higher than the measurement values from neutralisation mode $\mathrm{A}$ at $\mathrm{RH} \geq 90 \%$. For the small mass equivalent growth factors at lower relative humidities the parameterisation by Brechtel and Kreidenweis (2000) is not applicable. Moreover, its derivation from H-TDMA experiments may have been affected by similar chemical decompostion or restructuring effects as observed in our experiments with pure $\mathrm{NH}_{4} \mathrm{NO}_{3}$ particles. Nevertheless, the fair agreement of modelling and measurement results at high $R H$ confirms the suitability of the SS-VA modelling approach and the applicability of the parameterisation for $\Phi_{\mathrm{BSA}}$.

\section{Summary and conclusions}

In this study the H-TDMA technique and transmission electron microscopy have been used to investigate the hygroscopic growth and microstructural rearrangement of aerosol particles composed of the protein BSA and the inorganic salts $\mathrm{NaCl}$ and $\mathrm{NH}_{4} \mathrm{NO}_{3}$ upon interaction with water vapor.

To characterise the hygroscopic growth, microstructural rearrangements, and phase transitions (deliquescence, efflorescence) of pure and mixed protein and salt particles, their mobility equivalent diameters were measured as a function of relative humidity ( $R H=0-95 \%)$ in the two standard modes of H-TDMA operation, i.e. upon hydration (increasing $R H$ ) or dehydration (decreasing $R H$ ). In an additional third operation mode the size selected particles were conditioned at relative humidities of $0-95 \%$ but dried again upon particle 
sizing in the second DMA. This mode comprises a full cycle of hydration $\&$ dehydration and provides complementary information about microstructural rearrangement processes or chemical decomposition and volatilisation of the investigated particles upon surface interaction with water vapor, droplet formation and evaporation.

The measurement results have been compared to Köhler theory calculations of hygroscopic particle growth using different types of models. In the applied full parameterisation (FP) models both the water activity and density of the aqueous solution were calculated with empirical or semiempirical parameterisations. In the alternative volume additivity (VA) models only the water activity was calculated with parameterisations while the density of the mixture was assumed to be additively determined by the densities of the pure components (water, salt, protein).

For pure $\mathrm{NaCl}$ particles, a transformation from near-cubic or irregular to near-spherical shape was observed upon interaction with water vapor at relative humidities below the deliquescence threshold. The conversion was found to be kinetically limited on the second time-scale of the H-TDMA experiments and attributed to partial dissolution and recrystallisation of the salt surface. Deliquescence and efflorescence transitions and the hygroscopic growth of aqueous $\mathrm{NaCl}$ solution droplets were in good agreement with literature data and Köhler theory calculations.

Pure $\mathrm{NH}_{4} \mathrm{NO}_{3}$ particles exhibited no pronounced deliquescence or efflorescene transitions. Nevertheless, a hysteresis between hydration and dehydration was observed and attributed to decomposition and evaporation of $\mathrm{NH}_{4} \mathrm{NO}_{3}$ in highly supersaturated aqueous droplets. This process was negligible at very low and very high relative humidities. At $R H=50-80 \%$, however, it led to particle mobility diameter reductions of up to $10 \%$. Köhler theory calculations taking these effects into account were in fair agreement with the hygroscopic growth observed at $R H>80 \%$.

Pure BSA particles exhibited deliquescence and efflorescence transitions at $\sim 35 \% R H$ and a hygroscopic diameter increase by up to $\sim 10 \%$ at $95 \% R H$ in good agreement with model calculations based on a simple parameterisation of the osmotic coefficient derived from an osmotic pressure virial equation.

Mixed $\mathrm{NaCl}-\mathrm{BSA}$ and $\mathrm{NH}_{4} \mathrm{NO}_{3}$-BSA particles interacting with water vapor exhibited mobility diameter reductions of up to $20 \%$, depending on particle generation, conditioning, size, and chemical composition (BSA dry mass fraction 10$90 \%$ ). These observations can be explained by the formation of porous agglomerates due to ion-protein interactions and electric charge effects on the one hand, and by compaction of the agglomerate structure due to capillary condensation effects on the other. The size of $\mathrm{NH}_{4} \mathrm{NO}_{3}$-BSA particles was apparently also influenced by volatilisation of $\mathrm{NH}_{4} \mathrm{NO}_{3}$, but not as much as for pure salt particles, i.e. the protein inhibited the decomposition of $\mathrm{NH}_{4} \mathrm{NO}_{3}$ or the evaporation of the decomposition products $\mathrm{NH}_{3}$ and $\mathrm{HNO}_{3}$. Köhler theory cal- culations taking these effects into account were in fair agreement with the hygroscopic growth observed at $R H \geq 35 \%$ for $\mathrm{NaCl}-\mathrm{BSA}$ and at $R H \geq 90 \%$ for $\mathrm{NH}_{4} \mathrm{NO}_{3}$-BSA. The efflorescence threshold of $\mathrm{NaCl}$-BSA particles decreased with increasing BSA dry mass fraction (up to 5\% reduction of $R H_{\mathrm{e}}$ ), i.e. the protein inhibited the formation of salt crystals and enhanced the stability of supersaturated solution droplets.

The measurement and modeling results obtained for mixed protein-salt particles lead to the following general conclusions:

Depending on their origin and conditioning, aerosol particles containing inorganic salts and proteins or comparable organic macromolecules can have complex and highly porous microstructures, which are influenced by electric charge effects and interaction with water vapor. The proteins tend to be enriched at the particle surface and form an envelope which inhibits the access of water vapor to the particle core and leads to kinetic limitations of hygroscopic growth, phase transition, and microstructural rearrangement processes. Besides these surface and kinetic effects, proteins and comparable organic macromolecules may also influence the thermodynamic properties of the aqueous bulk solution (solubilities, vapor pressures, and chemical equilibria, e.g. for the decomposition and evaporation of $\mathrm{NH}_{4} \mathrm{NO}_{3}$ ).

These effects should be taken into account in the analysis of data from laboratory experiments and field measurements and in the modelling of aerosol processes involving particles with complex composition. They can strongly influence the outcome of experiments performed on multi-second time scales, and depending on ambient conditions they may also play a significant role in the atmosphere (deliquescence, efflorescence, droplet growth, and CCN activation). In fact, irregular hygroscopic growth curves with local minima and maxima similar to the ones observed in this study, have recently been reported by Gysel et al. (2004) from H-TDMA experiments with water-soluble organics extracted from real air particulate matter and with humic-like substances. Nevertheless, the hygroscopic growth of particles composed of inorganic salts and proteins or comparable organic substances at high relative humidities can be efficiently described with simple volume additivity models, provided that the correct dry solute mass equivalent diameter and composition are known. A simple parameterisation of the osmotic coefficient has been derived from the osmotic pressure virial equation by Carnahan and Starling (1969) and appears to be well-suited for proteins and comparable substances. It is fully compatible with traditional volume additivity models for salt mixtures, and for its application only the density and molar mass of the substance have to be known or estimated.

First results from ongoing investigations with additional chemical components like ammonium sulfate and humiclike substances confirm the above conclusions. We consider the observed effects (microstructural rearrangements, kinetic limitations, electric charge effects) and their mechanistic understanding highly relevant for the interpretation and analysis 
of laboratory and field measurement data of aerosol particles interacting with water vapor - especially but not only for $\mathrm{H}$ TDMA experiments. Moreover, we think that the presented Köhler theory calculations provide a basis for efficient modeling of the influence of macromolecular organics on the hygroscopic growth and $\mathrm{CCN}$ activation of atmospheric particles.

\section{Notation}

\begin{tabular}{|c|c|}
\hline Symb & \\
\hline$a_{\mathrm{W}}$ & water activity \\
\hline$A_{\Phi}$ & Debeye-Hückel coefficient \\
\hline$b_{\text {pit }}$ & ion-interaction parameter \\
\hline$c$ & polynomial coefficient (water activity) \\
\hline$C(D)$ & slip correction (Cunningham factor) \\
\hline$C_{\Phi}$ & ion-interaction parameter \\
\hline$d$ & polynomial coefficient (solution density) \\
\hline$D$ & particle diameter \\
\hline$f$ & envelope void fraction \\
\hline$g$ & growth factor \\
\hline$I$ & ionic strength \\
\hline$j, k$ & microstructural states \\
\hline$m$ & mass \\
\hline$M$ & molar mass \\
\hline$n$ & amount-of-substance (number of moles) \\
\hline$P_{\mathrm{os}}$ & osmotic pressure \\
\hline$q$ & counting variable \\
\hline$R$ & gas constant \\
\hline$R H$ & relative humidity \\
\hline$S_{\mathrm{W}}$ & water vapor saturation ratio \\
\hline$s$ & $\begin{array}{l}\text { solute (dissolved substance, consisting of one or } \\
\text { more chemical } \\
\text { compounds) }\end{array}$ \\
\hline$T$ & absolute temperature \\
\hline$V$ & molar volume \\
\hline$x$ & mass fraction \\
\hline$X$ & mole fraction \\
\hline$y$ & individual component of a solute mixture \\
\hline$Y_{\mathrm{f}}$ & ion-interaction parameter \\
\hline$z$ & charge number \\
\hline$\alpha, \beta$ & ion-interaction parameters \\
\hline$\delta$ & envelope porosity factor \\
\hline$\kappa$ & envelope shape factor \\
\hline$\lambda$ & mean free path \\
\hline$\chi$ & dynamic shape factor \\
\hline$\phi$ & volume fraction \\
\hline$\Phi$ & practical osmotic coefficient \\
\hline$\mu$ & molality \\
\hline$v$ & stoichiometric dissociation number \\
\hline$\rho$ & density \\
\hline$\sigma$ & surface tension \\
\hline$\sigma_{\mathrm{g}}$ & geometric standard deviation \\
\hline
\end{tabular}

Additional subscripts

\begin{tabular}{ll}
\hline $\mathrm{b}$ & mobility equivalent \\
$\mathrm{m}$ & mass equivalent \\
$\mathrm{i}$ & initial value (after DMA 1) \\
$\mathrm{d}$ & deliquescence \\
$\mathrm{e}$ & efflorescence \\
$\mathrm{de}$ & dehydration (H-TDMA mode 2) \\
hy & hydration (H-TDMA mode 1) \\
hlcorr & corrected for hydration layer \\
h\&d & hydration \& dehydration (H-TDMA mode 3) \\
min & minimum \\
$\mathrm{w}$ & water
\end{tabular}

Acknowledgements. This work has been funded by the German Federal Ministry of Education and Research (BMBF, AFO2000 Project 07ATC05, CARBAERO). The authors thank T. Franze, A. Messerer, U. Schaller, and A. Zerrath for practical support. The referees A. Laaksonen and E. Weingartner are gratefully acknowledged for stimulating comments and suggestions for improvement of the manuscript.

\section{References}

Allen, M. D. and Raabe, O. G.: Slip correction measurements of spherical solid aerosol particles in an improved Millikan apparatus, Aerosol Sci. Technol., 4, 269-286, 1985.

Andreae, M. O., and Crutzen, P. J.: Atmospheric aerosols: biogeochemical sources and role in atmospheric chemistry, Science, 276, 1052-1058, 1997.

Andrews, E., and Larson, S. M.: Effect of surfactant layers on the size changes of aerosol particles as a function of relative humidity, Environ. Sci. Technol., 27, 857-865, 1993.

Atkins, P. W.: Physical Chemistry, Oxford University Press, Oxford, 1982.

Austin, J., Shindell, D. , Beagley, S. , Brühl, C. , Dameris, M. Manzini, E. , Nagashima, T. , Newman, P. , Pawson, S. , Pitari, G., Rozanov, E. , Schnadt, C. and Shepherd, T.: Uncertainties and assessments of chemistry-climate models of the stratosphere, Atmos. Chem. Phys., 3, 1-27, 2003.

Baker, M. B.: Cloud microphysics and climate, Science, 276, 1072 1078, 1997.

Bergin, M. M., Ogren, J. A., Schwartz, S. E., and McInnes, L. M.: Evaporation of ammonium nitrate aerosol in a heated nephelometer: implications for field measurements, Environ. Sci. Technol., 31, 2878-2883, 1997.

Braun, C. and Krieger, U. K.: Two-dimensional light-scattering in aqueous $\mathrm{NaCI}$ single aerosol particles during deliquescence and efflorescence, Optics Express, 8, 314-321, 2001.

Brown, J. R.: Structure of Bovine serum albumin, Fed. Proc., 34, 591-591, 1975.

Brechtel, F. J., and Kreidenweis, S. M.: Predicting particle supersaturation from hygroscopic growth measurements in the Humidified TDMA. Part I: Theory and sensitivity studies., J. Atmos. Sci., 57, 1854-1871, 2000.

Brockmann, J. E., and Rader, D. J.: APS response to nonspherical particles and experimental determination of dynamic shape factor, Aerosol Sci. Technol., 13, 162-172, 1990. 
Brodskaya, E., Lyubartsev, A., and Laaksonen, A.: Molecular dynamics simulations of water clusters with ions at atmospheric conditions, J. Chem. Phys., 116, 7879-7892, 2002.

Carnahan, N. F. and Starling, K. E.: Equation of state for nonattracting rigid spheres, J. Chem. Phys., 51, 635-636, 1969.

Chan, K. C., Flagan, R. C., and Seinfeld, J. H.: Water activities of $\mathrm{NH}_{4} \mathrm{NO}_{3} /\left(\mathrm{NH}_{4}\right)_{2} \mathrm{SO}_{4}$ solutions, Atmos. Environ., 26A, 1661$1671,1992$.

Chan, M. N.; Chan, C. K.: Hygroscopic properties of two model humic-like substances and their mixtures with inorganics of atmospheric importance, Environ. Sci. Technol., 37, 5109-5115, 2003.

Cziczo D.: Interactive comment on Effects of the physical state of tropospheric ammonium-sulfate-nitrate particles on global aerosol direct radiative forcing by S. T. Martin et al., Atmos. Chem. Phys. Discuss., 3, S1882-S1883, 2003

Clegg, S. L. and Pitzer, K. S.: Thermodynamics of multicomponent, miscible, ionic solutions: generalised equations for symmetrical electrolytes, J. Phys. Chem., 96, 3513-3520, 1992.

Clegg, S. L., Brimblecombe, P., and Wexler, A. S.: Thermodynamic model of the system $\mathrm{H}^{+}-\mathrm{NH}_{4}^{+}-\mathrm{SO}_{4}^{2-}-\mathrm{NO}_{3}^{-}-\mathrm{H}_{2} \mathrm{O}$ at tropospheric temperatures, J. Phys. Chem. A., 102, 2137-2154, 1998.

Colberg, C. A., Luo, B. P., Wernli, H., Koop, T., and Peter, Th.: A novel model to predict the physical state of atmospheric $\mathrm{H}_{2} \mathrm{SO}_{4} / \mathrm{NH}_{3} / \mathrm{H}_{2} \mathrm{O}$ aerosol particles, Atmos. Chem. Phys., 3, 909, 2003.

Corrigan, C. E. and Novakov, T.: Cloud condensation nucleus activity of organic compounds: a laboratory studies. Atmos. Environ., 33, 2661-2668, 1999.

Cruz, C. N. and Pandis, S. N.: A study of the ability of pure secondary organic aerosol to act as cloud condensation nuclei, Atmos. Environ., 31, 2205-2214, 1997.

Cruz, C. N., Dassius, K. G., and Pandis, S. N.: The effect of dioctyl phthalate films on the ammonium nitrate aerosol evaporation rate, Atmos. Environ., 34, 3897-3905, 2000.

Decesari, S., Facchini, M. C., Matta, E., Lettini, F., Mircea, M., Fuzzi, S., Tagliavini, E., and Putaud, J.-P.: Chemical features and seasonal variation of fine aerosol water-soluble organic compounds in the Po Valley, Italy, Atmos. Environ., 35, 3691-3699, 2001.

Derjaguin, B. V., Churaev, N. V., and Muller, V. M.: Surface forces, Plenum, New York, 1987.

Facchini, M. C., Fuzzi, S., Zappoli, S., Andracchio, A., Gelencsér, A., Kiss, G., Krivácsy Z., Mészáros, E., Hansson H.-C., Alsberg, T., and Zebühr, Y.: Partitioning of the organic aerosol component between fog droplets and interstitial air, J. Geophys. Res., 104, 26821-26832, 1999a.

Facchini, M. C., Mircea, M., Fuzzi, S., and Charison, R. J.: Cloud albedo enhancement by surface-active organic solutes in growing droplets, Nature, 401, 257-259, 1999 b.

Feder, J.: Fractals, Plenum Press, New York, London, 1988.

Finlayson-Pitts, B. J., and Pitts, Jr., J. N.: Tropospheric air pollution: ozone, airborne toxics, polycyclic aromatic hydrocarbons, and particles, Science, 276, 1045-1052, 1997.

Finlayson-Pitts, B. J., and Pitts Jr., J. N.: Chemistry of the upper and lower atmosphere, Academic Press, San Diego, 2000.

Foster, M., and Ewing, G. E.: An infrared spectroscopic study of water thin films on $\mathrm{NaCl}$ (100), Surface Sci., 427-428, 102-106, 1999.
Franze, T., Zerrath A., Weller M. G., Niessner, R., and Pöschl, U.: Analysis of biopolymers in road dust and atmospheric aerosol samples, J. Aerosol Sci., 32, S502-S502, 2001.

Franze, T., Krause, K., Niessner, R., and Pöschl, U.: Proteins and amino acids in air particulate matter, J. Aerosol Sci., 34, S777S778, 2003a.

Franze, T., Weller M. G., Niessner, R., and Pöschl, U.: Enzyme immunoassays for the investigation of protein nitration by air pollutants, Analyst, 128, 824-831, 2003b.

Fuchs, N. A.: The mechanics of aerosols, Pergamon Press, Oxford, 1964.

Gill, P. S., Graedel, T. E., and Weschler, C. J.: Organic films on atmospheric aerosol particles, fog droplets, raindrops, and snowflakes, Rev. Geophys. Space Phys., 21, 903-920, 1983.

$\mathrm{Gu}$, Y. and Li, D.: Measurements of electric charge and surface potential on small aqueous drops in the air by applying the Millikan method, Colloid Surfaces A: Physicochem. Eng. Aspects, 137, 205-215, 1998.

Gysel, M., Weingartner, E., and Baltensperger, U.: Hygroscopicity of aerosol particles at low temperatures. 2. Theoretical and experimental hygroscopic properties of laboratory generated aerosol, Environ. Sci. Technol., 36, 63-68, 2002.

Gysel, M., Weingartner, E., Nyeki, S., Paulsen, D., Baltensperger, U., Galambos, I., and Kiss, G.: Hygroscopic properties of water-soluble matter and humic-like organics in atmospheric fine aerosol, Atmos. Chem. Phys., 4, 35-50, 2004.

Hämeri, K., Rood, M. J., and Hansson, H.-C.: Hygroscopic properties of a $\mathrm{NaCl}$ aerosol coated with organic compounds, J. Aerosol Sci., 23, S437-S440, 1992.

Hämeri, K., Väkevä, M., Hansson, H.-C., and Laaksonen, A.: Hygroscopic growth of ultrafine ammonium sulphate aerosol measured using an ultrafine tandem differential mobility analyzer, J. Geophys. Res., 105, 22 231-22 242 , 2000.

Hänel, G.: The properties of atmospheric aerosol particles as functions of the relative humidity at thermodynamic equilibrium with the surrounding moist air, Rev. Geophys., 17, 73-188, 1976.

Hansson, H.-C., Wiedensohler, A., Rood, M. J., and Covert, D. S.: Experimental determination of the hygroscopic properties of organically coated aerosol particles, J. Aerosol Sci., 21, S241S244, 1990.

Havers, N., Burba, P., Lambert, J., and Klockow, D.: Spectroscopic characterization of humic-like substances in airborne particulate matter, J. Atmos. Chem., 29, 45-54, 1998.

Hinds, W. C.: Aerosol technology: Properties, behavior, and measurement of airborne particles, 2nd, edited by John Wiley \& Sons, New York, 1999.

Iziomon, M. G. and Lohmann, U.: Characteristics and direct radiative effect of mid-latitude continental aerosols: the ARM case, Atmos. Chem. Phys., 3, 1903-1917, 2003.

Jacobson, M. C., Hansson, H. C., Noone, K. J., and Charlson R. J.: Organic atmospheric aerosol: Review and state of the science, Rev. Geophys., 38, 267-294, 2000.

Joutsensaari, J., Vaattovaara, P., Vesterinen, M., Hämeri, K., and Laaksonen A.: A novel tandem differential mobility analyzer with organic vapor treatment of aerosol particles, Atmos. Chem. Phys., 1, 51-60, 2001.

Kärcher, B.: Simulating gas-aerosol-cirrus interactions: Processoriented microphysical model and applications, Atmos. Chem. Phys., 3, 1645-1664, 2003. 
Kelly, W. P. and McMurry, P. H.: Measurement of particle density by inertial classification of differential mobility analyzergenerated monodisperse aerosols, Aerosol. Sci. Technol., 17, 199-212, 1992.

Köllensperger, G., Friedbacher, G., Kotzick, R., Niessner, R., and Grasserbauer, M.: In-situ atomic force microscopy investigations of aerosols exposed to different humidities, Fres. J. Anal. Chem., 364, 296-304, 1999.

Kotzick, R. and Niessner, R.: The effects of aging processes on critical supersaturation ratios of ultrafine carbon aerosol, Atmos. Environ., 33, 2669-2677, 1999.

Krämer, L., Pöschl, U., and Niessner, R.: Microstructural rearrangement of sodium chloride condensation aerosol particles on interaction with water vapor, J. Aerosol Sci., 31, 673-684, 2000.

Kulmala, M. , Suni, T. , Lehtinen, K. , Dal Maso, M. , Boy, M. , Reissell, A. , Rannik, Ü. , Aalto, P. , Keronen, P. , Hakola, H. , Bäck, J., Hoffmann, T. , Vesala, T. and Hari, P.: A new feedback mechanism linking forests, aerosols, and climate, Atmos. Chem. Phys. Discuss., 3, 6093-6107, 2003.

Kumar, P. P., Broekhuizen, K., and Abbatt, J. P. D.: Organic acids as cloud condensation nuclei: Laboratory studies of highly soluble and insoluble species, Atmos. Chem. Phys., 3, 949-982, 2003.

Lightstone, J. M., Onasch, T. B., Imre, D., and Oatis, S.: Deliquescence, efflorescence, and water activity in ammonium nitrate and mixed ammonium nitrate/succinic acid microparticles, J. Phys. Chem., 104, 9337-9346, 2000.

Liu, B. Y. H., Pui, D. Y. H., Whitby, K., Kittelson, D. B., Kousaka, Y., and McKenzie, R. L.: The aerosol mobility chromatograph: a new detector for sulfuric acid aerosols, Atmos. Environ., 12, 99-104, 1978.

Mainelis, G., Willeke, K., Baron, P., Reponen, T., Grinshpun, S., Gorny, R. L., and Trakumas, S.: Electrical charges on airborne microorganisms, J. Aerosol Sci., 32, 1087-1110, 2001.

Malm, C. W. and Day, D. E.: Estimates of aerosol species scattering characteristics as a function of relative humidity, Atmos. Environ, 35, 2845-2860, 2001

Martin, S. T.: Phase transitions of aqueous atmospheric particles, Chem. Rev., 100, 3403-3453, 2000.

Martin, S. T., Hung, H.-M., Park, R. J., Jacob, D. J., Spurr, R. J. D., Chance, K. V., and Chin, M.: Effects of the physical state of tropospheric ammonium-sulfate-nitrate particles on global aerosol direct radiative forcing, Atmos. Chem. Phys., 4, 183-214, 2004.

Martin, S. T. and Bertram, A. K.: Interactive comment on "Effects of the physical state of tropospheric ammonium-sulfate-nitrate particles on global aerosol direct radiative forcing" by S. T. Martin et al., Atmos. Chem. Phys. Discuss., 3, S2445-S2448, 2003.

Maling, A., Wiedensohler, A., Busch, B., Neusüss, C., Quinn, P., Bates, T., and Covert, D.: Hygroscopic properties of different aerosol types over the Atlantic and Indian Oceans, Atmos. Chem. Phys., 3, 1377-1397, 2003.

Matta, E., Facchini, M. C., Decesari, S., Mircea, M., Cavalli, F., Fuzzi, S., Putaud, J.-P., and Dell'Acqua, A.: Mass closure on the chemical species in size-segregated atmospheric aerosol collected in an urban area of the Po Valley, Italy, Atmos. Chem. Phys., 3, 623-637, 2003.

Miguel, A. G., Cass, G. R., Glovsky, M. M., and Weiss, J.: Allergens in paved road dust and airborne particles, Environ. Sci. Technol., 33, 4159-4168, 1999.

Mikhailov, E. F., Vlasenko, S. S., Kiselev, A. A., and Rushkevich,
T. I.: Modification of carbon clusters fractal structure due to cappilary forces, in Fractal Frontiers, edited by Novak, M. M. and Dewey, T. G., World Scientific, Singapore, New Jersey, London, Hong Kong, 1997.

Mikhailov, E. F., Vlasenko, S. S., Krämer, L., and Niessner, R.: Interaction of soot aerosol particles with water droplets: influence of surface hydrophilicity, J. Aerosol Sci., 32, 697-711, 2001.

Mikhailov, E., Vlasenko, S., Niessner, R., and Pöschl, U.: Interactive comment on "Interaction of aerosol particles composed of protein and salts with water vapor: hygroscopic growth and microstructural rearrangement: by E. Mikhailov et al., Atmos. Chem. Phys. Discuss., 3, S2479-S2484, 2003.

Ming, Y. and Russell, L. M.: Predicted hygroscopic growth of sea salt aerosol, J. Geophys. Res., 106, 28 259-28 274, 2001.

Mokbel, I., Ye, S., Jose, J., and Xans, P.: Study of non ideality of various aqueous sodium chlorid solutions by vapor pressures measurements and correlation of experimental results by Pitzer's method, J. Chim, Phys, 94, 122-137, 1997.

Moya, M., Pandis, S. N., and Jacobson, M. Z.: Is the size distribution of urban aerosols determined by thermodynamic equilibrium? An application to Southern California, Atmos. Environ., 36, 2349-2365, 2002.

Mukai, A. and Ambe, Y.: Characterization of humic acid-like brown substance in airborne particulate matter and tentative identification of its origin, Atmos. Environ., 20, 813-819, 1986.

Niessner, R. and Helsper, C.: Application of a multistep condensation nuclei counter as a detector for particle surface composition, J. Aerosol Sci., 16, 201-209, 1985

Niessner, R., Däumer, B., and Klockow, D.: Investigations on the surface properties of ultrafine aerosols by means of a multistep condensation nuclei counter, Fres. Z. Anal. Chem., 333, 129$133,1989$.

Paunov, V. N., Dimova, R. I., Kralchevsky, P. A., Broze, G., and Mehreteab, A.: The hydration repulsion between charged surfaces as an interplay of volume exclusion and dielectric saturation effects, J. Colloid Interface Sci., 182, 239-248, 1996.

Petsev, N. D., Thomas, B. R., Yau, S.-T., and Vekilov, P. G.: Interactions and aggregation of apoferritin in solution: Effects of added electrolytes, Biophys. J., 78, 2060-2069, 2000.

Peters Jr., T.: Serum Albumin. Adv. Protein Chem., 37, 161-245, 1985.

Pitzer, K. S.: Activity coefficients in electrolyte solutions, 2nd ed., CRC Press, Roca Raton, 1991.

Pitzer, K. S.: Thermodynamics of electrolytes. I. Theoretical basis and general equations. J. Phys. Chem., 77, 268-277, 1973.

Pitzer, K. S. and Mayorga, G.: Thermodynamics of electrolytes. II. Activity and osmotic coefficients for strong electrolytes with one or both ions univalent, J. Phys. Chem., 77, 2300-2308, 1973.

Pöschl, U.: Formation and decomposition of hazardous chemical components contained in atmospheric aerosol particles, J. Aerosol Med., 15, 203-212, 2002.

Pöschl, U.: Aerosol particle analysis: challenges and progress, Anal. Bioanal. Chem., 375, 30-32, 2003.

Prenni, A. J., DeMott, P. J., Kreidenweis, S. M., Sherman, D. E., Russell, L. M., and Ming, Y.: The Effects of Low Molecular Weight Dicarboxylic Acids on Cloud Formation, J. Phys. Chem. A, 105, 11 240-11 248, 2001.

Prenni, A. J., DeMott, P. J., and Kreidenweis, S. M.: Water uptake of internally mixed particles containing ammonium sulfate and 
dicarboxylic acids, Atmos. Environ., 37, 4243-4251, 2003.

Pruppacher, H. R. and Klett, J. D.: Microphysics of clouds and precipitation, 2nd ed., Kluwer Academic Publishers, Dordrecht, 1997.

Pszenny, A. A. P., Moldanova, J., Keene, W. C., Sander, R., Maben, J. R., Martinez, M., Crutzen, P. J., Perner, D., and Prinn, R. G.: Halogen cycling and aerosol $\mathrm{pH}$ in the Hawaiian marine boundary layer, Atmos. Chem. Phys., 4, 147-168, 2004.

Rader, D. J. and McMurry, P. H.: Application of the Tandem Differential Mobility Analyzer to studies of droplet growth and evaporation, J. Aerosol Sci., 17, 771-788, 1986.

Ramanathan, V., Crutzen, P. J., Kiehl, J. T., and Rosenfeld, D.: Aerosols, climate and the hydrological cycle, Science, 294, 2119-2124, 2001.

Ramaswamy, V., Boucher, O., Haigh, J., et al.: Climate Change 2001: The scientific basis (Working group I to the third assessment report of the IPCC), Cambrige Univ. Press, Cambrige, 349416, 2001

Ravishankara, A. R.: Heterogeneous and multiphase chemistry in the troposphere, Science, 276, 1058-1065, 1997.

Richardson, C. B. and Hightower, R. L.: Evaporation of ammonium nitrate particles, Atmos. Environ., 21, 971-975, 1987.

Robinson, R. A. and Stokes, R. H.: Electrolyte solutions, 2nd ed., Butterworths, London, 1970.

Rogge, W. F., Mazurek, L. M., Hildemann L. M., and Cass, G. R.: Quantification of urban organic aerosol at a molecular level: identification, abundance and seasonal variation, Atmos. Environ., 27A, 1309-1330, 1993.

Russell, L. M., Maria, S. F., and Myneni, S. C. B.: Mapping organic coatings on atmospheric particles, Geophys. Res. Lett., 29,10.1029/2002GL014874, 2002.

Saxena, P., Hildemann, L. M., McMurry, P. H., and Seinfeld J. H.: Organics alter the hygroscopic behavior of atmospheric particles, J. Geophys. Res., 100, 18 755-18 770, 1995.

Saxena, P. and Hildemann, L. M.: Water-soluble organics in atmospheric particles: A critical review of the literature and application of thermodynamics to identify candidate compounds, J. Atmos. Chem., 24, 57-109, 1996.

Schneider, J., Borrmann, S., Wollny, A. G., Bläsner, M., Mihalopoulos, N., Oikonomou, K., Sciare, J., Teller, A., Levin, Z., and Worsnop, D. R.: Online mass spectrometric aerosol measurements during the MINOS campaign (Crete, August 2001), Atmos. Chem. Phys., 4, 65-80, 2004.

Sciare, J., Cachier, H., Oikonomou, K., Ausset, P., Sarda-Estéve, R., and Mihalopoulos, N.: Characterization of carbonaceous aerosols during the MINOS campaign in Crete, July-August 2001: a multi-analytical approach, Atmos. Chem. Phys., 3, 1743-1757, 2003.

Seinfeld, J. H. and Pandis, S. N.: Atmospheric chemistry and physics - from air pollution to climate change, John Wiley \& Sons, New York, 1998.

Shulman, M. L., Jacobson, M. C., Carlson, R. J., Synovec, R. E., and Young, T. E.: Dissolution behavior and surface tension effects of organic compounds in nucleating cloud droplets, Geoph. Res. Letters, 23, 277-280, 1996.

Tanford, C.: Physical chemistry of macromolecules, J. Wiley \& Sons, New York, 1961.
Tang, I. N.: Chemical and size effects of hygroscopic aerosols on light scattering coefficients, J. Geophys. Res., 101, 19245$19250,1996$.

Tang, I. N.: Phase transformation and growth of hygroscopic aerosols, in Aerosol Chemical Processes in the Environment; edited by Spurny, K. R. and Hochrainer, D., CRC Press LLC, Boca Raton, 61-80, 2000.

Tang, I. N., Munkelwitz, H. R., and Davis, J. G.: Aerosol growth studies - II. Preparation and growth measurements of monodisperse salt aerosols, J. Aerosol Sci., 8, 149-159, 1977.

Tang, I. N. and Munkelwitz, H. R.: Composition and temperature dependence of the deliquescence properties of hygroscopic aerosol, Atmos. Environ., 27A, 467-473, 1993.

Ten Brink, H. M., Kruisz, C., Kos, G. P. A., and Berner, A.: Composition/size of the light-scattering aerosol in the Netherlands, Atmos. Environ., 31, 4955-3962, 1997.

Tsigaridis, K. and Kanakidou, M.: Global modelling of secondary organic aerosol in the troposphere: a sensitivity analysis, Atmos. Chem. Phys., 3, 1849-1869, 2003.

Turpin, B. J., Saxena, P., Andrews, E.: Measuring and simulating particulate organics in the atmosphere: problems and prospects, Atmos. Environ., 34, 2983-3013, 2000.

Väkevä, M., Kulmala, M., Stratmann, F., and Hämeri, K.: Field measurements of hygroscopic properties and state of mixing of nucleation mode particles, Atmos. Chem. Phys., 2, 55-66, 2002.

Verwey, E. J. and Overbeek, J. T. G.: Theory and stability of lyophobic colloids, Elsevier, Amsterdam, 1948.

Weast, R. C.: Handbook of chemistry and physics, 69th ed., CRC Press, 1988.

Weingartner, E., Burtscher, H., and Baltensperger, U.: Hygroscopic properties of carbon and diesel soot particles, Atmos. Environ., 31, 2321-2327, 1997.

Weingartner, E., Gysel, M., and Baltensperger, U.: Hygroscopicity of aerosol particles at low temperatures. 1. New low-temperature H-TDMA instrument: setup and first applications, Environ. Sci.Technol., 6, 55-62, 2002.

Wexler, A. S. and Clegg S. L.: Atmospheric aerosol models for systems including the ions $\mathrm{H}^{+}, \mathrm{NH}_{4}^{+}, \mathrm{Na}^{+}, \mathrm{SO}_{4}^{2-}, \mathrm{NO}_{3}^{-}, \mathrm{Cl}^{-}$, $\mathrm{Br}^{-}$and $\mathrm{H}_{2} \mathrm{O}$, J. Geophys. Res., 107 (D14), art. no. 4207, 2002.

Willeke, K. and Baron, P. A.: Aerosol measurements-Principles, Techniques, and Applications. Van Nostrand Reinhold, New York, 1993.

Weis, D. D. and Ewing, G. E.: Water content and morpology of sodium chloride aerosol particles, J. Geoph. Res., 104, 17, 21 275-21 285, 1999.

Xiong, J. Q., Zhong, M., Fang, C., Chen, L. C., and Lippmann, M.: Influence of organic films on the hygroscopicity of ultrafine sulfuric acid aerosol, Environ. Sci. Technol., 32, 3536-3541, 1998.

Zappoli, S, Andracchio, A., Fuzzi, S., Facchini, M. C., Gelensér, A., Kiss, G., Krivácsy, Z., Molnár, A., Mészáros, E., Hansson, H C., Rosman, K., and Zebühr, Y.: Inorganic, organic and macromolecular components of fine aerosol in different areas of Europe in relation to their water solubility, Atmos. Environ., 33, 2733 2743, 1999.

Zhang, Q. and Anastasio, C.: Free and combined amino compounds in atmospheric fine particles (PM2.5) and fog waters from Northern California, Atmos. Environ., 37, 2247-2258, 2003. 